OPEN ACCESS

Edited by:

Stanislav Kopriva,

University of Cologne, Germany

Reviewed by:

Jinpeng Gao,

Washington State University, USA

Gang Li,

University of Nebraska-Lincoln, USA

${ }^{*}$ Correspondence:

Pengfei $\mathrm{Xu}$

xupengfei@neau.edu.cn

Shuzhen Zhang

zhangshuzhen@neau.edu.cn

†These authors have contributed equally to this work.

Specialty section:

This article was submitted to Plant Physiology,

a section of the journal

Frontiers in Plant Science

Received: 14 November 2016 Accepted: 20 February 2017

Published: 07 March 2017

Citation:

Zhao Y, Chang X, Qi D, Dong L, Wang $G$, Fan $S$, Jiang $L$, Cheng $Q$, Chen X, Han D, Xu P and Zhang S (2017) A Novel Soybean ERF

Transcription Factor, GmERF113, Increases Resistance to Phytophthora sojae Infection in Soybean.

Front. Plant Sci. 8:299. doi: 10.3389/fpls.2017.00299

\section{A Novel Soybean ERF Transcription Factor, GmERF113, Increases Resistance to Phytophthora sojae Infection in Soybean}

\author{
Yuanling Zhao ${ }^{1,2 t}$, Xin Chang ${ }^{1 \dagger}$, Dongyue Qi't, Lidong Dong ${ }^{1}$, Guangjin Wang ${ }^{2}$, \\ Sujie Fan', Liangyu Jiang', Qun Cheng ${ }^{1}, X_{i}$ Chen ${ }^{1}$, Dan Han', Pengfei X ${ }^{1 *}$ and \\ Shuzhen Zhang ${ }^{1 *}$
}

${ }^{1}$ Key Laboratory of Soybean Biology of Chinese Education Ministry, Soybean Research Institute, Northeast Agricultural University, Harbin, China, ${ }^{2}$ Biotechnology Research Institute, Heilongjiang Academy of Agricultural Sciences, Harbin, China

Phytophthora root and stem rot of soybean caused by the oomycete Phytophthora sojae, is a destructive disease worldwide. Ethylene response factors (ERFs) play important roles in regulating plant biotic and abiotic stress tolerance. In this study, a new ERF gene, GmERF113, was isolated from the highly resistant soybean 'Suinong 10.' Sequence analysis suggested that the protein encoded by GmERF113 contained a conserved AP2/ERF domain of 58 amino acid and belonged to the B-4 subgroup of the ERF subfamily. Expression of GmERF113 was significantly induced by P. sojae, ethylene, and methyl jasmonate. GmERF113 protein localized to the nucleus when transiently expressed in Arabidopsis protoplasts, could bind to the GCC-box, and acted as a transcription activator. In addition, a region of the full-length GmERF113, GmERF113-II, interacted with a basic helix-loop-helix transcription factor (GmbHLH) in yeast cells. Fulllength GmERF113 also interacted with GmbHLH in planta. GmERF113-overexpressing transgenic plants in susceptible cultivar 'Dongnong 50' soybean exhibited increased resistance to $P$. sojae and positively regulated the expression of the pathogenesis-related genes, $P R 1$ and $P R 10-1$. These results indicate that GmERF113 may play a crucial role in the defense of soybean against $P$. sojae infection.

\section{Keywords: Glycine max, Phytophthora sojae, GmERF113, AP2/ERF, activator}

\section{INTRODUCTION}

Phytophthora root rot, caused by the oomycete pathogen Phytophthora sojae, is a destructive disease of soybean worldwide (Wrather et al., 1997; Tyler, 2007) which commonly reduces soybean yields by between 10 and 40\% (Bailey et al., 2003); severe infection can even result in a total yield loss (Zhang S.Z. et al., 2010). To better understand the resistance mechanisms of soybean plants under $P$. sojae-induced stress, it is essential to study the genes involved, as these will provide information useful for genetic engineering and breeding.

Manipulation of transcription factors is an important tool for improvement of plant tolerance against adverse environmental conditions. Numerous studies have demonstrated important roles for ethylene responsive factors (ERFs) in regulation of pathogenesis-related (PR) gene expression (Lorenzo et al., 2003; Pieterse et al., 2009; Rehman and Mahmood, 2015). 
The AP2/ERF transcription factor superfamily is divided into three groups, designated the AP2, RAV, and ERF families, based on their numbers of AP2/ERF domains and sequence similarities (Nakano et al., 2006). The AP2/ERF domain contains two conserved elements, the YRG and RAYD element (Okamuro et al., 1997). The YRG element contains conserved a WAAEIRD box amino acid (AA) sequence, which is involved in regulating the specificity of the DNA binding of these transcription factors (Okamuro et al., 1997). The central region of the RAYD element contains an amphipathic $\alpha$-helix, which has a crucial role in mediation of protein-protein interactions (Okamuro et al., 1997). ERF family proteins contain a single AP2/ERF domain consisting of 58-59 AA residues, and are divided into the CBF/DREB and ERF subfamilies (Sakuma et al., 2002). CBF/DREB transcription factors contain valine (V) and glutamic acid (E) in the conserved DNA-binding domain, and are further sub-classified into A1 to A-6 subgroups on the basis of their conserved domains (Sakuma et al., 2002). These proteins are primarily involved in responses to abiotic stress through recognition of dehydrationresponsive or cold-repeat elements (DRE/CRT) containing the core motif, A/GCCGAC (Yamaguchi-Shinozaki and Shinozaki, 1994; Thomashow, 1999). ERF subfamily proteins contain an alanine (A, position 14) and an aspartic acid (D, position 19) in the conserved DNA-binding domain, and are further subdivided into subgroups B-1 to B-6 (Sakuma et al., 2002). ERFs bind to the cis-acting GCC-box (AGCCGCC) element, to mediate their crucial role in the response of plants to biotic stress (Ohme-Takagi and Shinshi, 1995; Hao et al., 1998).

Ethylene response factors function as transcription activators or repressors regulating both basal transcription levels of target genes and the activity of other transcription factors (Okamuro et al., 1997; Gu et al., 2000; Xu et al., 2007; Maruyama et al., 2013; Bui et al., 2015). For example, constitutive expression of the AtERF1 gene elevates expression of pathogen-inducible plant defensin (PDF1.2), conferring resistance to necrotrophic fungi (Berrocallobo et al., 2002; Lorenzo et al., 2003); NtERF5 and TiERF1 enhance resistance to TMV (Fischer and DrogeLaser, 2004; Liang et al., 2008); and AtERF5 and BrERF11 increase resistance to bacteria and fungi, respectively (Son et al., 2012; Lai et al., 2013). In contrast, the transcription repressors AtERF3/4 decrease disease resistance (Fujimoto et al., 2000; Yang et al., 2005), and VpERF1 can increase susceptibility to both bacterial and fungal pathogens (Zhu et al., 2013).

Some ERF subfamily members also respond to phytohormones and abiotic stress in plants (Shinozaki et al., 2003; Pieterse et al., 2009; Sugano et al., 2013). Transcription of the TaERF1 gene can be induced by exogenous abscisic acid (ABA), ethylene (ET), and salicylic acid (SA). Furthermore, overexpression of TaERF1 activates stress-related genes, improving abiotic stress tolerance in transgenic plants (Xu et al., 2007). Expression of GmERF7 is induced by treatment with methyl jasmonate (MeJA), ET, and ABA, and its overexpression enhances salt tolerance in transgenic tobacco plants (Zhai et al., 2013b). Moreover, overexpression of AhERF019, a peanut ERF gene, enhances tolerance to drought, heat, and salt stress in transgenic Arabidopsis (Wan et al., 2014), and mutation of ERF-associated amphiphilic repression (EAR) motif in OsERF3 represses ET biosynthesis and drought tolerance in rice (Zhang et al., 2013). Thus, ERF proteins have important roles, not only in pathogen defense responses, but also in tolerance to various abiotic stress factors.

Many ERFs interact with other proteins to regulate the expression of their target genes (Cheong et al., 2003; Song et al., 2005; De Boer et al., 2011). Xu et al. (1998) reported that nitrilase-like protein (NLP), an enzyme involved in auxin biosynthesis, interacts with tobacco EREBP2/3 and tomato Pti4/5/6 in regulation of $\mathrm{PR}$ gene expression. The interaction between NtERF3 and NtUBC2 is likely to be critical for downregulation of the repression activity of NtERF3 (Koyama et al., 2003). In addition, TaERF1 interacts with TaMAPK1, enhancing the activity of TaERF1 (Xu et al., 2007). In wheat, the ERF factor, W17, interacts with the HSP90 and PPR proteins, which may have significant transcriptional regulation roles (Qiu et al., 2011). The above examples demonstrate that the activities of ERF transcription factors can be modified by protein-protein interactions (Schwechheimer and Bevan, 1998; Li et al., 2011; Zhao et al., 2015).

In a previous study, we constructed a cDNA library from soybean 'Suinong 10' (which has high resistance to P. sojae) by suppression subtractive hybridization (SSH). The library was enriched for mRNAs encoding expressed sequence tags (ESTs) which increased in abundance during infection with $P$. sojae. In this study, an EST homologous to the AP2/ERF transcription factor, GmERF113 (GenBank accession no. XM_003548806, NCBI protein no. XP_003548854), was isolated and its characteristics and expression patterns in response to different stress conditions analyzed, demonstrating that GmERF113 has a role in the defense response of soybean to P. sojae.

\section{MATERIALS AND METHODS}

\section{Plant Material and Stress Treatments}

The soybean cultivar 'Suinong10', which is frequently used to study gene-for-gene resistance against the predominant race of P. sojae (race 1) in Heilongjiang, China (Zhang S.Z. et al., 2010), was used in this study. Plant stress treatments were performed at the first-node stage (Fehr et al., 1971). For hormone treatments, soybean seedlings were sprayed with $100 \mu \mathrm{M}$ MeJA, $100 \mu \mathrm{M}$ $\mathrm{ABA}$, or $500 \mu \mathrm{M}$ SA. ET treatment was performed in sealed plexiglass chambers by application of $2 \mathrm{ml}$ of $40 \%$ Ethephon and $1 \mathrm{~g}$ of $\mathrm{NaHCO}_{3}$ dissolved in $200 \mathrm{ml} \mathrm{H}_{2} \mathrm{O}$. During the early phase of stress treatment, leaves were collected at $0,3,6,9,12$, and $24 \mathrm{~h}$. Infection with $P$. sojae race 1 was performed using zoospores, following the methods described by Ward et al. (1979) and Morris et al. (1991), with minor modifications. The concentration of zoospores was estimated using a hemocytometer, and adjusted to approximately $1 \times 10^{5}$ spores $\mathrm{mL}^{-1}$. Leaves were collected at 0,6 , $12,24,36,48$, and $72 \mathrm{~h}$ after treatment, immediately snap-frozen in liquid nitrogen, and stored at $-80^{\circ} \mathrm{C}$ for quantitative real-time PCR (qRT-PCR) analysis. 
The soybean cultivar 'Dongnong 50', which is susceptible to $P$. sojae race 1 , was used for gene transformation experiments and was obtained from the Key Laboratory of Soybean Biology in the Chinese Ministry of Education, Harbin.

\section{Isolation of the GmERF113 Gene}

Functional ESTs $(n=375)$ were isolated from an SSH cDNA library from the $P$. sojae resistant soybean cultivar, 'Suinong 10, inoculated with $P$. sojae race 1 , which was constructed in our laboratory (Xu et al., 2012). NCBI BLAST ${ }^{1}$ searches using these ESTs identified a cDNA clone highly homologous to plant ERF transcription factors. This clone was designated GmERF113 (GenBank accession no. XM_003548806, NCBI protein no. XP_003548854), and amplified by RT-PCR from soybean 'Suinong 10' cDNA using the primers GmERF113F and GmERF113R (Supplementary Table 1) which were designed based on flanking sequences identified by searching the Phytozome database ${ }^{2}$. PCR was performed as follows: $94^{\circ} \mathrm{C}$ for $3 \mathrm{~min}$, followed 35 cycles of $94^{\circ} \mathrm{C}$ for $30 \mathrm{~s}, 60^{\circ} \mathrm{C}$ for $30 \mathrm{~s}$, and $72^{\circ} \mathrm{C}$ for $1 \mathrm{~min}$, with a final extension at $72^{\circ} \mathrm{C}$ for $10 \mathrm{~min}$. The PCR product was gel purified and cloned into the pMD18-T vector (TaKaRa, Dalian, China) and sequenced (GENEWIZ, Beijing, China). An analysis of the predicted structure of the protein encoded by GmERF113 (GmERF113) was performed using Smart ${ }^{3}$. Sequence alignments were conducted using DNAMAN software ${ }^{4}$. A phylogenetic analysis of GmERF113 and various heterologous AP2/ERF members was performed using the Neighbor-joining method in MEGA 5.1 software.

\section{Quantitative Real-Time PCR Analysis}

Quantitative real-time PCR analysis was performed using a realtime RT-PCR kit (Takara, Japan) according to the manufacturer's instructions, on a CFX96 Touch $^{\mathrm{TM}}$ Real-Time PCR Detection System (Bio-Rad, USA). Total RNA was extracted from soybean leaves using Trizol reagent (Invitrogen, Shanghai, China) and $1 \mu \mathrm{g}$ was converted to first-strand cDNA using an M-MLV reverse transcriptase kit (Takara, Dalian, China). Amplification was performed using the primer pair GmERF113-qF and GmERF113-qR (Supplementary Table 1). For tissue distribution analysis, the transcript levels of the GmEF1 $\beta$ gene (GenBank accession no. NM_001248778) were used as an internal control (Supplementary Table 1 for primer sequences). The soybean housekeeping gene GmActin4 (GenBank accession no. AF049106) was used as an internal control (see Supplementary Table 1 for primer sequences) for treatments with abiotic and biotic stresses. Relative expression levels were calculated using the $2^{-\Delta \Delta C t}$ method. qRT-PCR analysis was performed using three biological replicates (i.e., RNA samples extracted from three independent plants) and three technical replicates of each biological replicate.

\footnotetext{
${ }^{1}$ http://blast.ncbi.nlm.nih.gov/Blast.cgi

${ }^{2}$ http://www.phytozome.net/

${ }^{3}$ http://smart.embl-heidelberg.de/

${ }^{4}$ http://www.lynnon.com/
}

\section{Subcellular Localization of the GmERF113 Protein}

The coding region of GmERF113 was cloned into the NcoI/SpeI sites of the pCAMBIA1302 vector using the primers, GmERF113GF and GmERF113-GR (Supplementary Table 1), to produce the construct 35S:GmERF113-GFP; the empty vector, 35S:GFP, was used as a control. The transient expression of green fluorescent protein (GFP)-fused proteins in Arabidopsis protoplast cells was performed as described by Yoo et al. (2007). Transfected cells were observed using a confocal laser scanning microscope (Leica TCSSP2, Germany).

\section{Purification of Fusion Proteins and Electrophoretic Mobility Shift Assays (EMSAs)}

The full-length coding region of GmERF113 was inserted into the NdeI/SacI sites of the pET29b(+) vector (Novagen, Germany) using the primers GmERF113-EF and GmERF113-ER (Supplementary Table 1) to create pET29b(+)-GmERF113. The recombinant fusion plasmid was transformed into Escherichia coli strain BL21 (DE3). Over-expression of the cloned genes was induced using $0.5 \mathrm{mM}$ isopropyl- $\beta$-D-thiogalactoside (IPTG) at $37^{\circ} \mathrm{C}$ for $4 \mathrm{~h}$. For recombinant protein purification, bacterial cells were pelleted after induction, resuspended in $10 \mathrm{~mL}$ icecold $1 \times$ Binding Buffer $(0.5 \mathrm{M} \mathrm{NaCl}, 20 \mathrm{mM}$ Tris- $\mathrm{HCl}, 5 \mathrm{mM}$ imidazole, $\mathrm{pH}$ 7.9), and sonicated on ice for $10 \mathrm{~min}(30 \mathrm{~s}$ pulse/min), until samples were no longer viscous. Following centrifugation at $12000 \times \mathrm{g}$ for $15 \mathrm{~min}$ at $4^{\circ} \mathrm{C}$, supernatants were harvested and loaded onto His-bind Resin columns (EMD Millipore, USA). $1 \times$ Elution Buffer $(0.5 \mathrm{M} \mathrm{NaCl}, 20 \mathrm{mM}$ Tris$\mathrm{HCl}, 1 \mathrm{M}$ imidazole, $\mathrm{pH}$ 7.9) was added to elute the recombinant GmERF113 protein. EMSAs were performed as described by Liu et al. (2006).

\section{Yeast One-Hybrid Assay}

To further analyze the ability of GmERF113 to bind to GCC-box motifs, coding regions of GmERF113 were amplified and cloned into the EcoRI/BamHI sites of the GAL4 activation vector (pGADT7) (see Supplementary Table 1 for primer sequences) and the specific DNA fragments, GCC (ATCCATAAGAGCCG CCACTAAAATAAGACCGATCAA) and mutated GCC (mGCC) (ATCCATAAGATCCTCCACTAAAATAAGACCGAT CAA) were cloned into the pHIS2 vector. Competent yeast cells (strain Y187) were prepared according to the Clontech Yeast Protocols Handbook. For yeast transformation, $50 \mu \mathrm{l}$ of competent yeast cells were incubated with 100 ng of pHIS2 bait vector and $100 \mathrm{ng}$ of pGADT7 prey vector, $50 \mu \mathrm{g}$ of salmon sperm carrier DNA, and $0.5 \mathrm{ml}$ of PEG/LiAc solution. Transformations were plated onto SD (-Trp, -Leu) media to select co-transformed cells and incubated at $28^{\circ} \mathrm{C}$ for 4 days. Transformed yeast cells were subsequently grown in SD (-Trp, -Leu) liquid media to an $\mathrm{OD}_{600}$ of 0.1 . Aliquots of each transformed yeast cells $(5 \mu \mathrm{l})$ were spotted on SD (-Trp, -Leu) and SD (-Trp, -His, -Leu) media plates supplemented with $100 \mathrm{mM} 3$-amino-1,2,4-triazole (3-AT) (Sigma-Aldrich). The plates were then incubated for 3 days at $28^{\circ} \mathrm{C}$. 
A

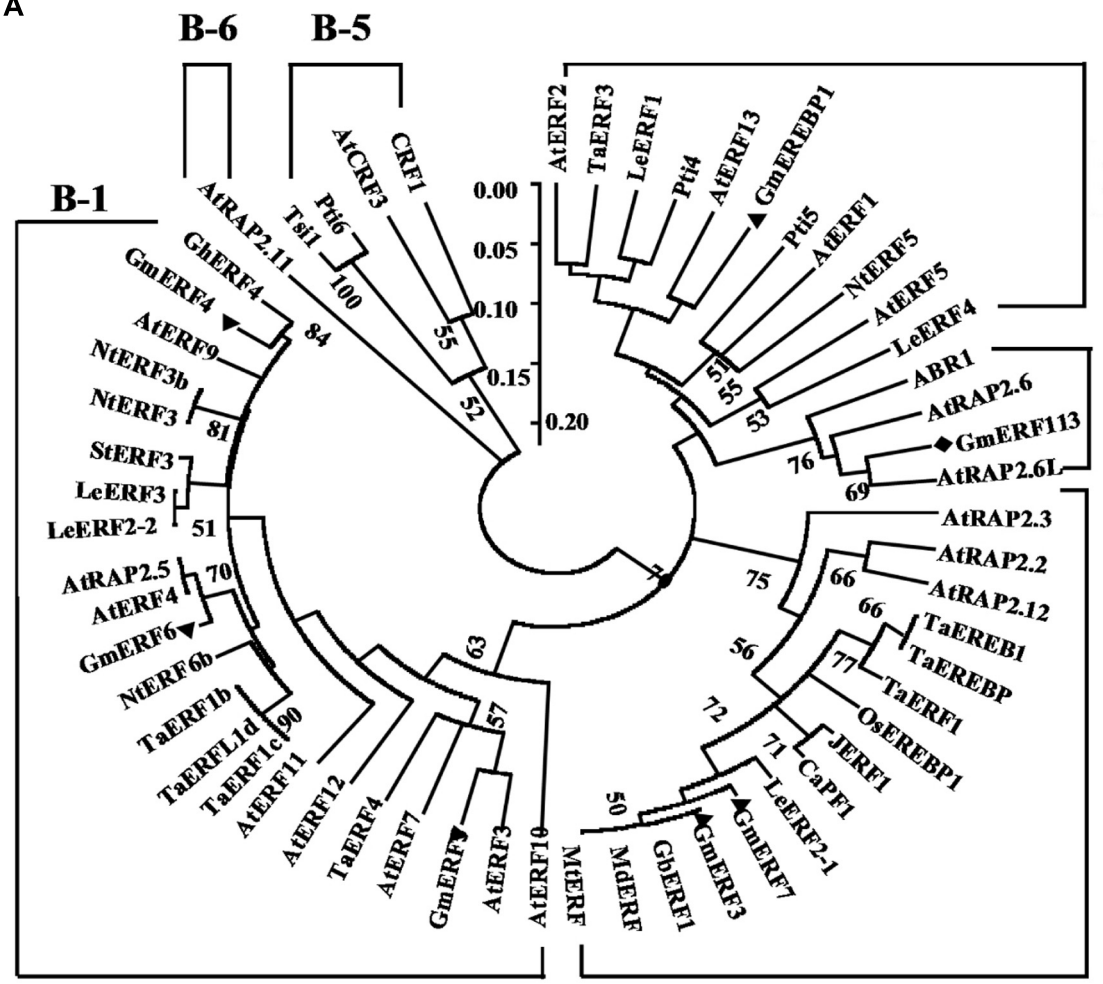

B

ABR1

AtRAP2.6

AtRAP2.6L

GmERF113

\section{B -sheet-1}

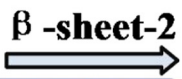

B -sheet-3
C

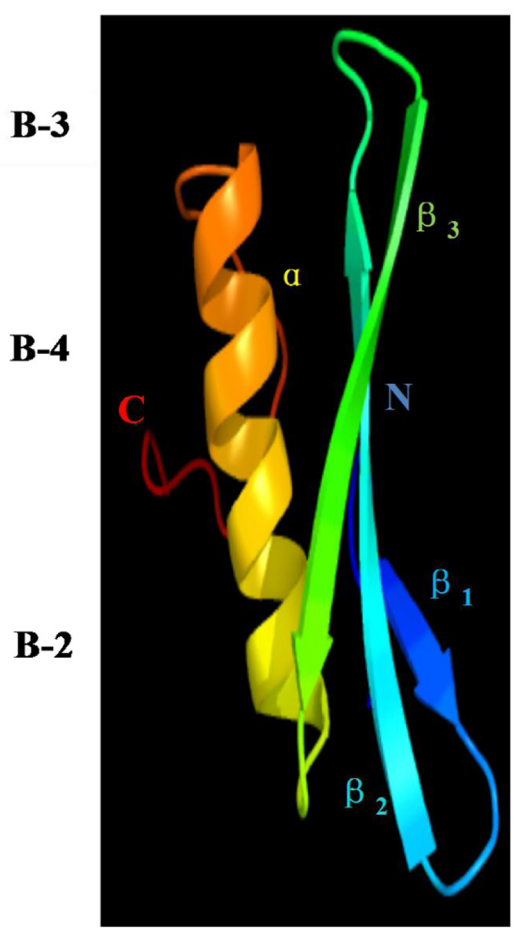

a -helix

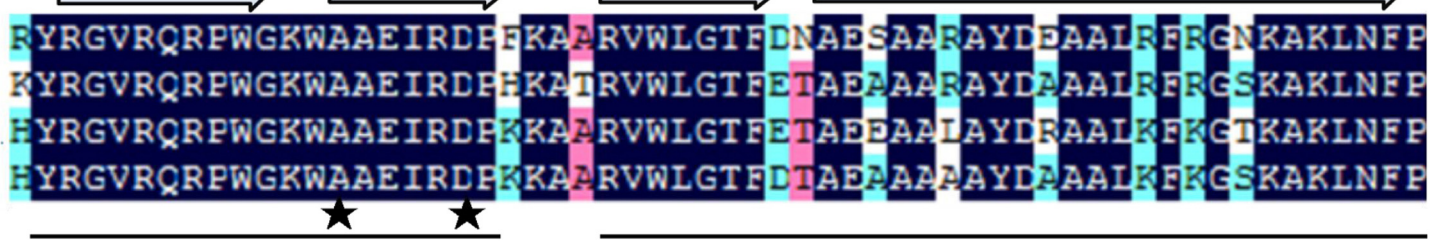

YRG element

\section{RAYD element}

FIGURE 1 | Amino acid (AA) sequence comparison between GmERF113 and AP2/ERF-related proteins. (A) Phylogenetic analysis of GmERF113 and other AP2/ERF transcription factors. The phylogenetic tree was constructed using the NJ method in MEGA5.1. The numbers on the tree branches represent values of reliability. GenBank accession numbers are as follows: AtERF1 (NP188965), AtERF2 (NP199533), AtERF3 (NP175479), AtERF4 (NP188139), AtERF5 (NP568679), AtERF7 (NP188666), AtERF9 (NP199234), AtERF10 (NP171876), AtERF11 (NP174159), AtERF12 (NP174158), AtERF13 (NP182011), AtRAP2.2 (NP566482), AtRAP2.3 (NP188299), AtRAP2.5 (EFH59179), AtRAP2.6 (NP175008), AtRAP2.6L (NP196837), AtRAP2.11 (NP197480), AtRAP2.12 (NP175794), CRF1 (NP192852), AtCRF3 (NP200141), ABR1 (NP201280), TaERF1 (AY271984), TaERF1b (DQ334413), TaERF1c (DQ334414), TaERF1d (DQ334415), TaERF3 (EF570122), TaERF4 (JX014257), TaEREB1 (AY781352), TaEREBP (AJ515477), GmERF3 (EU681278), GmERF4 (EU747723), GmERF5 (HQ896930), GmERF6 (JN416601), GmERF7 (JN416602), GmEREBP1 (AF357211), Tsi1 (AF058827), NtERF3 (AB573717), NtERF3b (AB573716), NtERF5 (AY655738), NtERF6b (AB573719), LeERF1 (AY192367), LeERF2-1 (AY192368), LeERF2-2 (AY275554), LeERF3 (AY192369), LeERF4 (NP001234313), JERF1 (AY044235), Pti4 (LEU89255), Pti5 (LEU89256), Pti6 (LEU89257), OsEREBP1 (AF193803), GhERF4 (AY781120), StERF3 (EF091875), MtERF (AES84434), MdERF (GU732435), GbERF1 (AY572463), and CaPF1 (AY246274). (B) Alignment of the AA sequences of the conserved AP2/ERF domain of B-4 group proteins. The three $\beta$-sheets and one $\alpha$-helix of the AP2/ERF domain are marked above the corresponding sequences. The YRG and RAYD elements are indicated below the alignment. The alanine and aspartic acid residues at positions 14 and 19 in the AP2/ERF domain are marked by asterisks. (C) Predicted three-dimensional structure of the AP2/ERF domain of GmERF113.

\section{Transactivation Assays}

For transactivation assays, plasmids were constructed according to the method described by Chen et al. (2009). The $\beta$-glucuronidase (GUS) gene in pCAMBIA3301 ${ }^{5}$ was replaced by GmERF113, placing the gene under the control of the cauliflower mosaic virus (CaMV) $35 \mathrm{~S}$ promoter in the effector

${ }^{5} \mathrm{http}: / /$ www.cambia.org plasmid. To construct the reporter plasmid, four copies of the GCC-box motif and flanking sequence from the RD29A gene promoter were cloned upstream of the CaMV 35S promoter $(-42$ to +8$)$. The CaMV 35 S promoter contains a TATA box. This construct was inserted into pCXGUS-P, and fused to the GUS gene. Protoplast preparation and transfection were carried out according to the methods of Yoo et al. (2007). GUS activity was determined as described by Chen et al. (2006). 


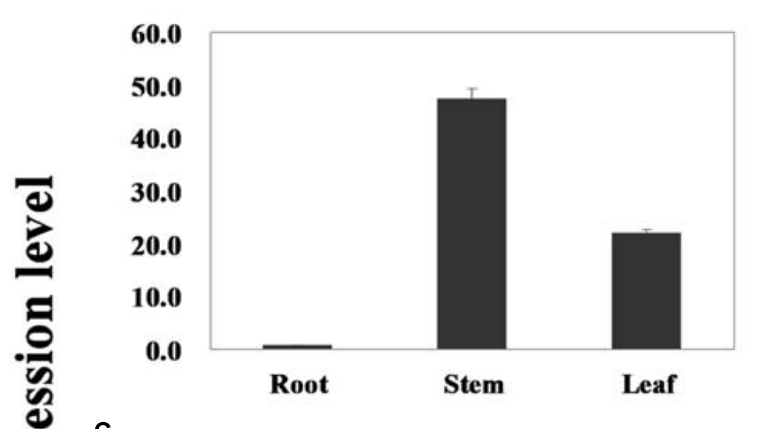

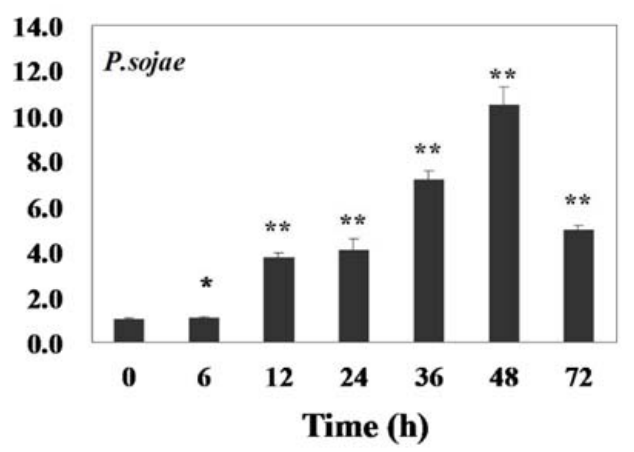

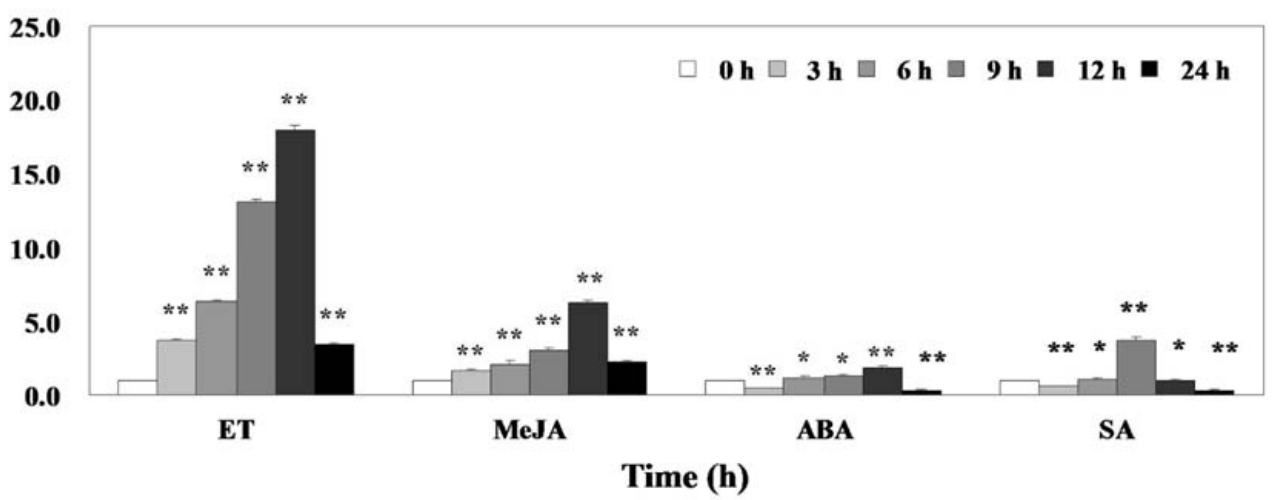

FIGURE 2 | Expression patterns of GmERF113 in soybean. Fourteen-day-old plants were collected for treatments and analyses. (A) GmERF113 mRNA levels in different tissues of soybean. Data were normalized to expression levels of soybean GmEF1 $\beta$. (B) GmERF113 expression in soybean leaves infected with Phytophthora sojae for 0, 6, 12, 24, 36, 48, and $72 \mathrm{~h}$. Data were normalized to expression levels of soybean GmActin4, and the relative expression of GmERF113 was compared with that in mock-treated plants at the same time points. (C) GmERF113 expression in soybean leaves in response to exogenous hormones: $100 \mu \mathrm{M}$ MeJA, $100 \mu \mathrm{M} \mathrm{ABA}$, and $500 \mu \mathrm{M}$ SA and ET treatments at 0, 3, 6, 9, 12, and $24 \mathrm{~h}$ after the initiation of treatments. Data were normalized to expression levels of soybean GmActin4, and are expressed as relative to that in mock-treated plants at the same time points. Three biological replicates, with three technical replicates each were averaged and statistically analyzed using Student's $t$-tests $\left({ }^{*} P<0.05,{ }^{* *} P<0.01\right)$. Bars indicate the standard error of the mean (SE).

\section{Transcription Activation Assays}

The full-length GmERF113 and two cDNA fragments (GmERF113-I encoding AAs 1-105 and GmERF113-II encoding AAs 1-183) were amplified by PCR using the appropriate primers (GmERF113-Y, GmERF113-IY, and GmERF113-IIY; see Supplementary Table 1). PCR was carried out using KOD-Plus-Neo DNA polymerase (Toyobo), with an initial denaturation step at $94^{\circ} \mathrm{C}$ for $3 \mathrm{~min}$, followed by 30 cycles at $94^{\circ} \mathrm{C}$ for $30 \mathrm{~s}, 60^{\circ} \mathrm{C}$ for $30 \mathrm{~s}$, and $68^{\circ} \mathrm{C}$ for $1 \mathrm{~min}$, with a final extension at $68^{\circ} \mathrm{C}$ for $8 \mathrm{~min}$. Transcription activation assays were performed in the yeast strain, Y2HGold, which contains the HIS3 and ADE2 reporter genes under distinct GAL4-responsive promoter elements. Purified PCR products were inserted into the EcoRI/PstI sites of the pGBKT7 vector. Fusion plasmids and the pGADT7 vector were transformed into the yeast strain Y2HGold (Clontech). Yeast cells were selected by growth on SD (-Trp, -Leu) and SD (-Trp, -Leu, -His, -Ade) media. As positive controls, the pGBKT7-P53 and pGADT7-SV40 plasmids were inserted into yeast Y2HGold cells, while yeast cells containing the pGBKT7-Lam and pGADT7-SV40 plasmids served as negative controls.

\section{Yeast Two-Hybrid Library Assays}

A cDNA library from soybean cultivar 'Suinong 10' inoculated with $P$. sojae zoospores was constructed using a Yeast Two Hybrid Library Construction kit (Clontech) in our laboratory (Dong et al., 2015). Screening for interacting proteins was performed following the manufacturer's protocols (Clontech). Approximately $1 \times 10^{7}$ transformants from the cDNA library were plated on SD selective (-Trp, -Leu, -His, -Ade) medium at $30^{\circ} \mathrm{C}$. Yeast colonies reaching diameters $>2 \mathrm{~mm}$ after $3-5$ days were cultured on SD selective (-Trp, -Leu, -His, -Ade) medium containing X- $\alpha$-Gal $\left(20 \mu \mathrm{g} \mathrm{mL}^{-1}\right)$ and aureobasidin A (125 $\mu \mathrm{g}$ $\mathrm{mL}^{-1}$ ). Blue colonies were characterized by PCR and sequencing. Yeast Y2HGold cells carrying pGBKT7-P53 and pGADT7-SV40 served as positive controls, whereas co-expression of pGBKT7lam and pGADT7-SV40 was used as a negative control.

Yeast two-hybrid $(\mathrm{Y} 2 \mathrm{H})$ experiments were performed as described by Wei et al. (2010). Full-length cDNAs of GmbHLH, pathogen-related protein-like $(G m P R P)$, homeobox-leucine zipper protein HAT5-like (GmHAT5), and long-chain-alcohol oxidase $(G m F A O)$ were amplified by PCR and cloned into pGADT7. Fusion plasmids and pGBKT7-GmERF113-II were 

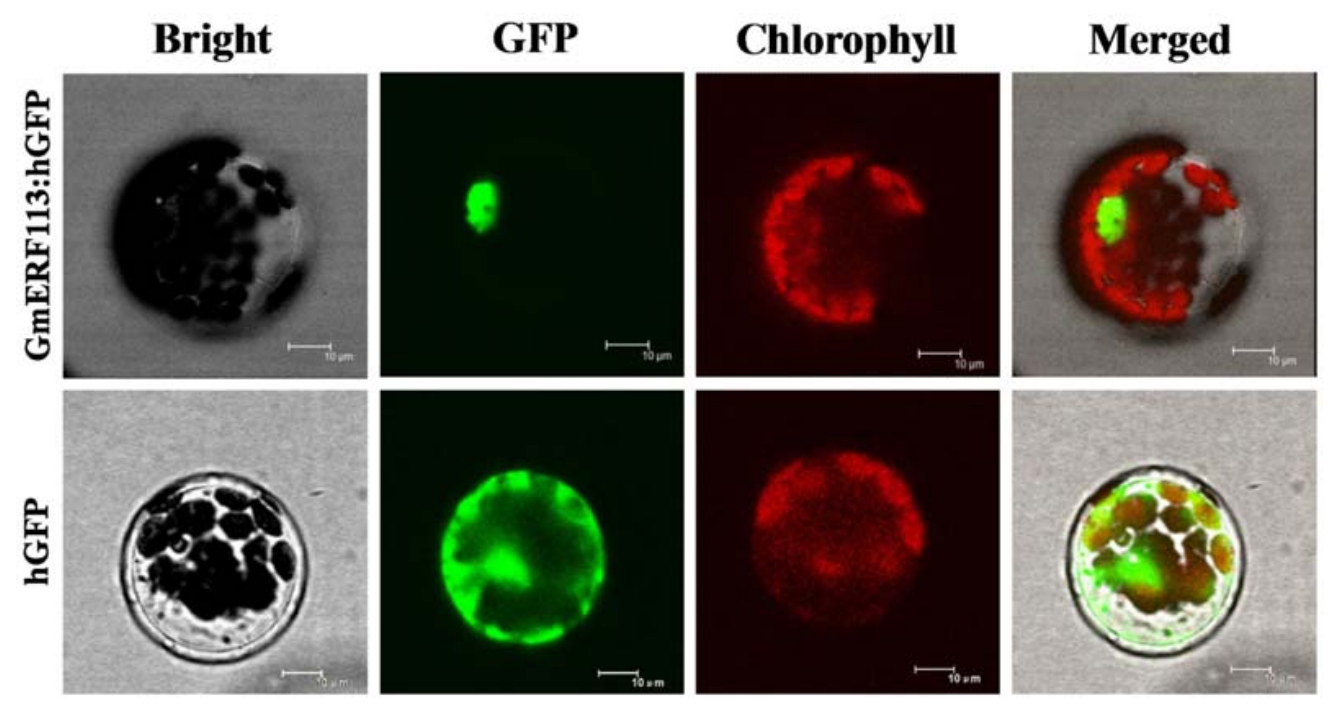

FIGURE 3 | Subcellular localization of the GmERF113 protein. Subcellular localization of GmERF113 was determined in Arabidopsis protoplasts using a confocal microscope. The fluorescence distribution of control humanized (h)GFP and the GmERF113-hGFP fusion protein are shown under bright-field, GFP fluorescence (green), and chlorophyll autofluorescence (red), along with combined images. All scale bars indicate $10 \mu \mathrm{m}$.

co-transformed into yeast strain Y2Hgold (Clontech). After selection at $30^{\circ} \mathrm{C}$, yeast colonies growing on SD (-Trp, -Leu) medium were transferred to SD (-Trp, -Leu, -His, -Ade) medium

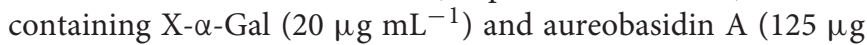
$\left.\mathrm{mL}^{-1}\right)$. Yeast cells carrying the pGBKT7-P53 and pGADT7SV40 plasmids were used as positive controls, and yeast cells harboring the pGBKT7- Lam and pGADT7-SV40 plasmids were used as negative controls.

\section{Bimolecular Fluorescence Complementation (BiFC) Assays}

For BiFC assays, the GmERF113 gene was cloned into pSAT6nEYFP-N1 and the full-length coding sequences of $G m b H L H$, GmPRP, GmHAT5, and GmFAO cDNA were also amplified by PCR and cloned into pSAT6-cEYFP-C1, respectively. These constructs were transiently transfected into Arabidopsis protoplasts using the polyethylene glycol method, as described by Yoo et al. (2007). Transfected cells were imaged using a TCS SP2 confocal spectral microscope imaging system (Leica).

\section{Soybean Transformation}

The full-length coding region of GmERF113 was PCR amplified with the primer pair GmERF113-TF and GmERF113-TR (Supplementary Table 1) and cloned into the BglII/BstEII sites of pCAMBIA3301, which contains the bar gene as a selective marker. The recombinant construct, 35S:GmERF113, was introduced into Agrobacterium tumefaciens strain LBA4404 using the freeze-thaw method (Holsters et al., 1978). Cotyledonary nodes of soybean 'Dongnong 50' were used as explants for transformation, using the Agrobacterium-mediated method described by Paz et al. (2004). Phosphinothricin $\left(8 \mathrm{mg} \mathrm{L}^{-1}\right)$ was added to shoot proliferation medium as a selective reagent.
$\mathrm{T}_{1}$ transgenic soybean plants were identified by daubing phosphinothricin (125 mg L $\mathrm{L}^{-1}$ ) on leaves and using PCR amplification with the primer pairs bar-F and bar- $\mathrm{R}$ to amplify regions of the bar reporter gene (see Supplementary Table 1 for primer sequences). $\mathrm{T}_{2}$ transgenic soybean plants were tested by PCR amplification and Southern blot hybridization using a DIG High Prime DNA Labeling and Detection Starter kit II (Roche, Germany).

\section{Expression Analysis of Putative GmERF113 Target Genes}

GmPR1 (XM_003545722) and GmPR10-1 (NM_001251335), which have GCC-box motifs in their promoters, were identified as putative downstream targets of GmERF113. Relative transcript abundance of GmERF113, GmPR1, and GmPR10-1 was compared between 35S:GmERF113 transgenic and wild-type soybean plants by qRT-PCR. The expression levels of the soybean GmEF1 $\beta$ gene were used as an internal control. Three biological replicates of qRT-PCR analyses were performed, using RNA samples extracted from three independent plants, with three technical replicates per plant.

\section{Assays of Pathogen Responses of Transgenic Soybean Plants}

Fully expanded leaves of $\mathrm{T}_{3}$ transgenic soybean plants, derived from $\mathrm{T}_{2}$ plants identified by PCR and Southern blot hybridization, were tested by qPCR using the primer pair, GmERF113-qF and GmERF113-qR (Supplementary Table 1) and screened for resistance to $P$. sojae as described by Kim et al. (2014), with some modifications. Live leaves inoculated with $P$. sojae were covered with polythene bags to maintain relative humidity levels; culture conditions were $25^{\circ} \mathrm{C}, 90 \% \pm 10 \%$ relative humidity, $16 \mathrm{~h}$ photoperiod, and $350 \mu \mathrm{mol} \mathrm{m} \mathrm{m}^{-2} \mathrm{~s}^{-1}$ 
A

GCC 5'-ATCCATAAGAGCCGCCACTAAAATAAGACCGATCAA-3' mGCC 5'-ATCCATAAGA TCCTCCACTAAAATAAGACCGATCAA-3'

\begin{tabular}{|c|c|c|c|}
\hline Lane & 1 & 2 & $\mathbf{3}$ \\
\hline Labeled GCC box & + & - & + \\
\hline Labeled mGCC box & - & + & - \\
\hline GmERF113 & + & + & + \\
\hline Competitor (100x) & $\mathbf{G C C}+$ & - & - \\
\hline
\end{tabular}

B

KDa M GmERF113

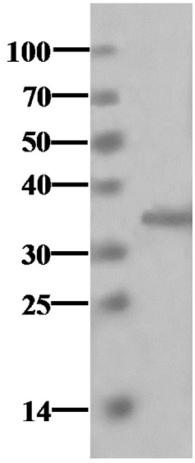

Complex

Free probe

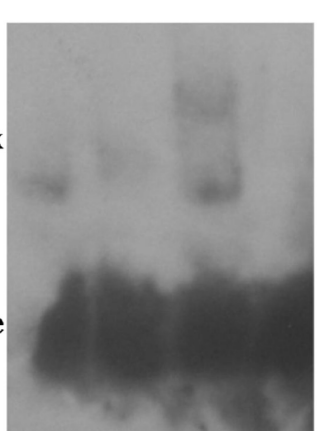

E

Reporter plasmid

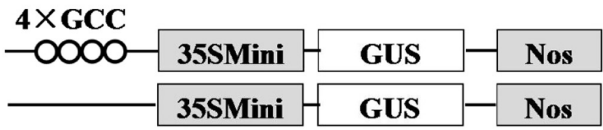

Effector plasmid

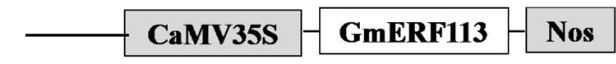

$\mathbf{F}$

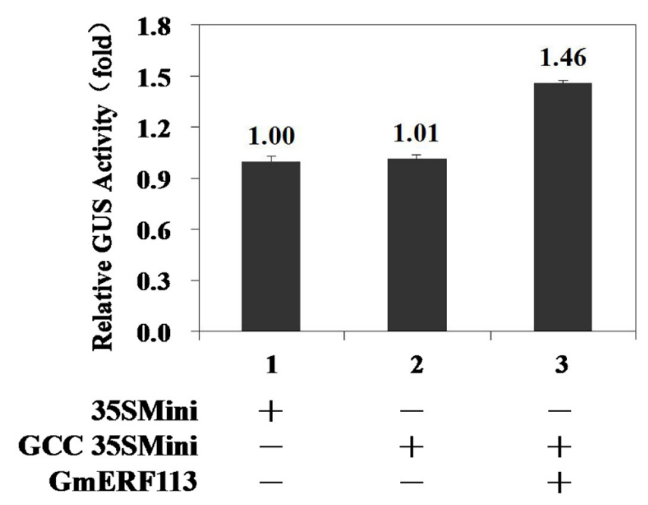

D

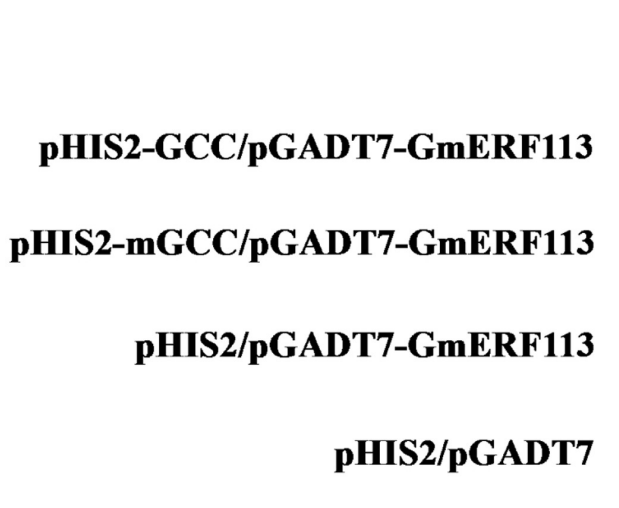

SD/-Trp,-Leu

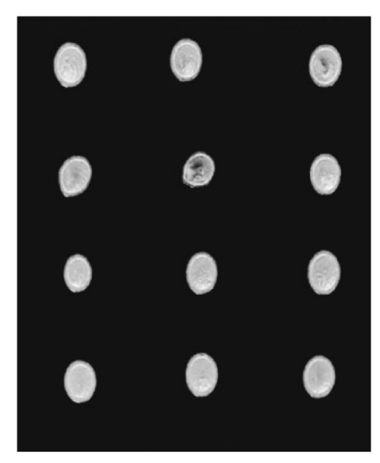

SD/-Trp,-Leu,-His $100 \mathrm{mM}$ 3-AT

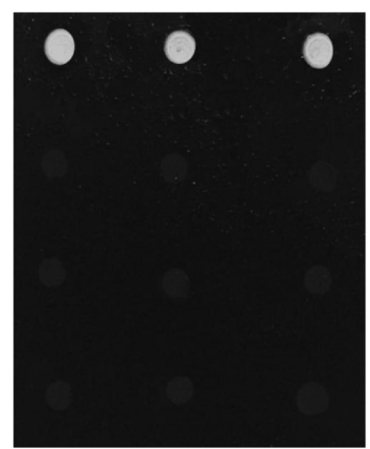

FIGURE 4 | Sequence-specific binding of GmERF113 to the GCC-box. (A) Nucleotide sequences of the GCC-box and mGCC-box probes. The core GCC sequences are underlined and the mutated nucleotides in the mGCC probe are in italics. (B) SDS-PAGE analysis of the purified recombinant GmERF113 protein using His-Bind Kits. (C) EMSA showing sequence-specific binding to the GCC-box of the recombinant GmERF113 protein. Lane 1, titration with cold GCC sequence as a competitor; lane 2, labeled mGCC probe and GmERF113 protein; lane 3, labeled GCC probe and GmERF113 protein; lane 4, free GCC probe only. (D) The binding activity of GmERF113 to the GCC-box sequence motif in a yeast one-hybrid assay. Yeast cells were selected on SD (-Trp, -Leu) and SD (-Trp, -Leu, -His) media plates supplemented with $100 \mathrm{mM}$ 3-amino-1,2,4-triazole (3-AT). (E) Schematic diagram of the reporter and effector plasmids. Reporter plasmids included four tandem copies of the GCC-box and 35Smini, and effector plasmids encoded GmERF113 under the control of the CaMV $35 S$ promoter. (F) Relative GUS activities in transactivation assays. The numbers represent the fold increase in GUS activity compared with the control vector GCC-box/35Smini promoter (GCC 35SMini) alone. Results are presented as averages of three replicates \pm standard deviation.

light intensity. Soybean 'Dongnong 50' plants were used as controls. After 2 and 4 days, disease symptoms on each leaf were observed and photographed using a Canon IXUS 860IS camera.

To investigate the responses of plants overexpressing GmERF113 to P. sojae infection, the cotyledons of $\mathrm{T}_{4}$ transgenic soybean plants at the first-node stage (V1) were inoculated with a suspension of $P$. sojae zoospores (Fehr et al., 1971) (concentration adjusted to approximately $8 \times 10^{5} \mathrm{~mL}^{-1}$ using a hemocytometer), generated according to the procedure described by Ward et al. (1979), with some modifications. The relative biomass of $P$. sojae in infected cotyledons was assessed after $48 \mathrm{~h}$ based on the transcript levels of the P. sojae TEF1 gene (GenBank accession no. EU079791) using soybean GmEF1ß as a reference gene, determined according to the method described by Chacón et al. (2010) (see Supplementary Table 1 for TEF1 and $G m E F 1 \beta$ primer sequences). For each experiment, three 
A

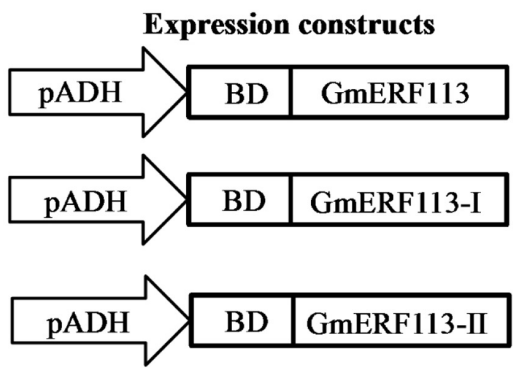

B

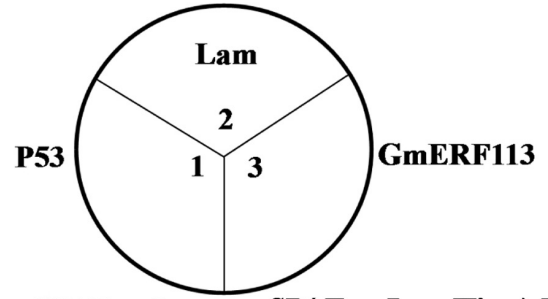

SD/-Trp,-Leu

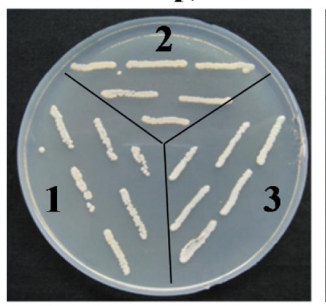

SD/-Trp,-Leu,-His,-Ade

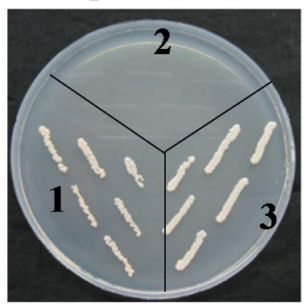

\section{Reporter constructs}
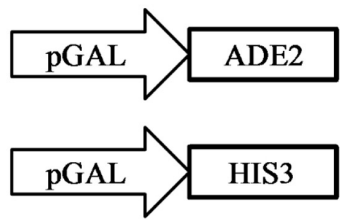

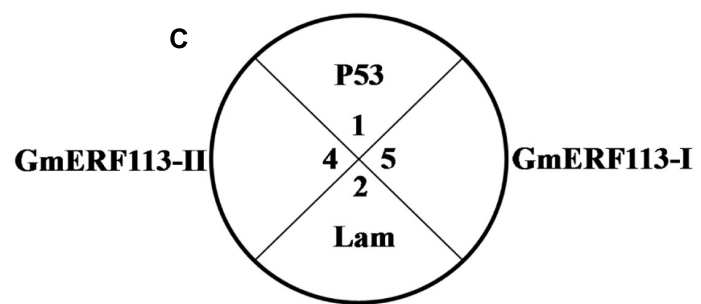

SD/-Trp,-Leu

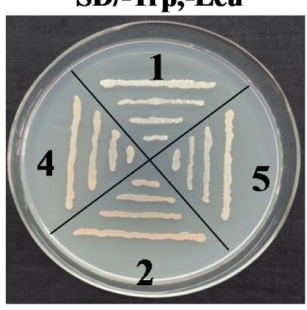

SD/-Trp,-Leu,-His,-Ade

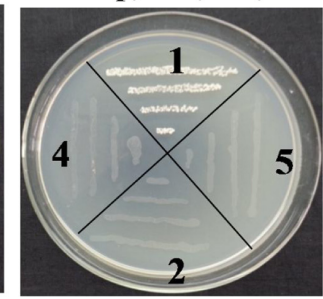

FIGURE 5 | GmERF113 transcription activation assay. The GmERF113 transcription activation assay was performed in the Y2HGold yeast strain. (A) Schematic diagram of the expression and reporter constructs. The GmERF113 gene was fused in-frame to the GAL4 DNA-binding domain (BD) expression vector and pGADT7, and transformed into yeast strain Y2HGold. The yeast strain Y2HGold contained the ADE2 and HIS3 reporter genes under distinct GAL4-responsive promoter elements. (B) The full-length GmERF113 transcription activation assay. (C) GmERF113-I and GmERF113-II transcription activation assay. Yeast cells were selected by growth on SD (-Trp, -Leu) and (-Trp, -Leu, -His, -Ade) media. Yeast Y2HGold cells carrying pGBKT7-P53 and pGADT7-SV40 served as positive controls, whereas co-expression of pGBKT7-lam and PGADT7-SV40 was used as a negative control (Clontech, USA).

biological replicates were performed, with three technical replicates each.

\section{RESULTS}

\section{Isolation and Sequence Analysis of GmERF113}

The full-length cDNA sequence of GmERF113 (GenBank accession no. XM_003548806, NCBI protein no. XP_003548854) was isolated from soybean 'Suinong 10' by RT-PCR. GmERF113 maps to chromosome 16 , and sequence analysis demonstrated that it was 1,259 bp in length, including 926 bp of intronic sequence. GmERF113 had an open reading frame (ORF) of $783 \mathrm{bp}$, encoding 260 AAs with a predicted molecular mass and pI of $28.72 \mathrm{kDa}$ and 6.15, respectively. The deduced GmERF113 protein contained a 58 AA conserved DNA-binding (AP2/ERF) domain, with alanine (A) and aspartic acid (D) at the 14 and 19th residues, respectively. The GmERF113N terminus included a basic AA region $\left(\mathrm{R}_{45} \mathrm{KRH}\right)$, predicted as putative nuclear localization signal, while the $\mathrm{C}$ terminus possessed a KKXXlike motif $\left(\mathrm{F}_{256} \mathrm{HDK}\right)$ (Supplementary Figure 1). Alignment and phylogenetic analysis indicated that GmERF113 was most similar to previously described ERF class B-4 subgroup members (ABR1, AtRAP2.6, and AtRAP2.6L) (Figure 1A). GmERF113 shared $84.5-91.4 \%$ AA identity of the AP2/ERF domain and $30.3-45.3 \%$ overall sequence AA identity with other members of the B-4 subgroup. The AP2/ERF domain contained two conserved segments, the YRG and RAYD elements (Figure 1B). Based on prediction of the three-dimensional structure of GmERF113 using Phyre $^{6}$, the protein has a long C-terminal $\alpha$-helix $(\alpha)$ wrapped in a three-stranded anti-parallel $\beta$-sheet $(\beta 1-\beta 3)$ (Figure 1C).

\section{Expression Patterns of GmERF113 under Different Stress Conditions}

Quantitative real-time PCR was performed to assess the transcript levels of GmERF113 in soybean 'Suinong 10' plants. The results demonstrated that the gene was constitutively expressed, with the highest levels in the stems, followed by the leaves and roots (Figure 2A). GmERF113 expression was responsive to exposure to $P$. sojae, ET, MeJA, ABA,

${ }^{6}$ http://www.sbg.bio.ic.ac.uk/phyre/ 
TABLE 1 | Part of library screening results by yeast two-hybrid.

\begin{tabular}{|c|c|c|}
\hline Gene & GenBank ID & $\begin{array}{l}\text { Number of } \\
\text { clones }\end{array}$ \\
\hline Pathogen-related protein-like (PRP) & LOC100805630 & 1 \\
\hline $\begin{array}{l}\text { Homeobox-leucine zipper protein } \\
\text { HAT5-like (HAT5) }\end{array}$ & LOC100804450 & 1 \\
\hline $\begin{array}{l}\text { Basic helix-loop-helix transcription } \\
\text { factor (bHLH) }\end{array}$ & LOC100806368 & 1 \\
\hline Long-chain-alcohol oxidase (FAO) & LOC100779139 & 1 \\
\hline Polyubiquitin-like & LOC100791065 & 2 \\
\hline Ubiquitin-conjugating enzyme E2 7-like & LOC100782328 & 1 \\
\hline UDP-glycosyltransferase 71C3-like & LOC100792458 & 1 \\
\hline Actin -3-like & LOC100781142 & 1 \\
\hline Synaptotagmin-2-like & LOC100778906 & 1 \\
\hline Protein S-acyltransferase 24-like & LOC100788923 & 1 \\
\hline $60 S$ ribosomal protein L38-like & LOC100795924 & 1 \\
\hline Adenosine kinase 2-like & LOC100780391 & 1 \\
\hline $\begin{array}{l}\text { Ribulose bisphosphate } \\
\text { carboxylase/oxygenase activase, } \\
\text { chloroplastic-like }\end{array}$ & LOC100797222 & 1 \\
\hline $\begin{array}{l}\text { Chlorophyll a-b binding protein of LHCII } \\
\text { type 1-like }\end{array}$ & LOC100796326 & 2 \\
\hline $\begin{array}{l}\text { Glyceraldehyde-3-phosphate } \\
\text { dehydrogenase chloroplastic-like } \\
\text { transcript variant X1 }\end{array}$ & LOC100806482 & 1 \\
\hline $\begin{array}{l}\text { Chlorophyll binding protein } 13 \text {, } \\
\text { chloroplastic-like }\end{array}$ & LOC100779387 & 1 \\
\hline $\begin{array}{l}\text { Plastid -lipid-associated protein } 4 \text {, } \\
\text { chloroplastic -like }\end{array}$ & LOC100803715 & 1 \\
\hline
\end{tabular}

and SA. Infection with $P$. sojae led to a gradual rise in GmERF113 mRNA levels, with the maximum level reached after $48 \mathrm{~h}$ (Figure 2B). Treatment with both ET and MeJA led to accumulation of GmERF113 transcripts within $3 \mathrm{~h}$, with expression levels reaching a maximum level $12 \mathrm{~h}$ after treatment, followed by a decline. In contrast, treatment with $\mathrm{ABA}$ and SA induced an initial down-regulation of GmERF113 transcription, followed by a slow increase, with maximum levels at 12 and $9 \mathrm{~h}$, respectively; however, the expression of GmERF113 was relatively low in response to these hormones, compared with that induced by exposure to P. sojae, ET, or MeJA (Figure 2C).

\section{Subcellular Localization of GmERF113}

To test the subcellular localization of GmERF113, a GmERF113GFP fusion protein expressed under the control of the CaMV $35 \mathrm{~S}$ promoter was transformed into Arabidopsis protoplasts. As shown in Figure 3, fluorescence of the control-hGFP protein was distributed throughout the cell, whereas that derived from the GmERF113-hGFP fusion protein was exclusively located in the nucleus, indicating that the GmERF113 protein exhibits nuclear localization.

\section{DNA Binding and Transcription Regulation Activity of GmERF113}

Electrophoretic mobility shift assays were performed to determine whether GmERF113 could bind to the cis-acting
GCC-box DNA element in vitro. Nucleotide sequences used for EMSAs, GCC, and mGCC, are presented in Figure 4A. The recombinant GmERF113 protein was purified using His-Bind Kits (EMD Millipore, USA) (Figure 4B). The results of the EMSA indicated that GmERF113 could recognize and bind to the GCC-box (Figure 4C, lane 3), but not the mutated GCC-box (mGCC-box) (Figure 4C, lane 2). Competition experiments were performed to determine the specificity of the mobility shift. When the ratio of unlabeled GCC probe to labeled GCC probe was approximately 100:1, the majority of labeled GCC probe was displaced (Figure 4C, lane 1), indicating that the GmERF113 protein can bind specifically to the GCC-box.

To further investigate the ability of GmERF113 to bind to GCC-box elements, yeast one-hybrid assays were performed. As shown in Figure 4D, GmERF113 specifically bound to the GCC-box element in yeast.

To determine whether GmERF113 could act as a transcriptional activator, we performed a transactivation assay in Arabidopsis protoplasts using a reporter gene that had four tandem copies of the GCC-box and effector plasmids with GmERF113 (Figure 4E). As shown in Figure 4F, GmERF113 led to a 1.46-fold higher transactivation of GCC-box-mediated transcription compared with the control, indicating that GmERF113 is able to activate transcription through this DNA element.

\section{Yeast Two-Hybrid Screening for GmERF113 Interacting Proteins}

Yeast two-hybrid analysis was performed to determine whether GmERF113 exhibited transcription activation activity in yeast cells using the expression constructs and reporter constructs (Figure 5A). The results demonstrated that full length GmERF113 could activate transcription in yeast (Figure 5B), while N-terminal fragments of the protein, GmERF113-I (AAs 1-105) and GmERF113-II (AAs 1-183) were not able to activate transcription in this context (Figure 5C). Therefore, GmERF113-II was used for screening the library.

Approximately $1 \times 10^{7}$ transformants from the Yeast Two Hybrid cDNA Library were screened on SD (-Trp, -Leu, -His, -Ade) medium, and 235 selected colonies with diameters $>2 \mathrm{~mm}$ were further cultured on SD selective (-Trp, -Leu, -His, -Ade) medium containing X- $\alpha$-Gal $(20 \mu \mathrm{g}$ $\mathrm{mL}^{-1}$ ) and aureobasidin A (125 $\left.\mu \mathrm{g} \mathrm{mL} \mathrm{mL}^{-1}\right)$. Among them, 53 blue colonies were characterized by analysis of their sequences using BLAST $^{7}$. ESTs from 17 candidate genes encoding proteins that might interact with GmERF113 were listed in Table 1. Homology analysis demonstrated that these candidate proteins were associated with signal transduction, biotic and abiotic stress, defense response, growth regulation, and photosynthesis.

\section{Interaction of GmERF113 with GmbHLH in Yeast and Planta}

In order to confirm which proteins interact with GmERF113II, four fusion genes from among the seventeen candidate

\footnotetext{
${ }^{7}$ http://blast.ncbi.nlm.nih.gov/Blast.cgi
} 


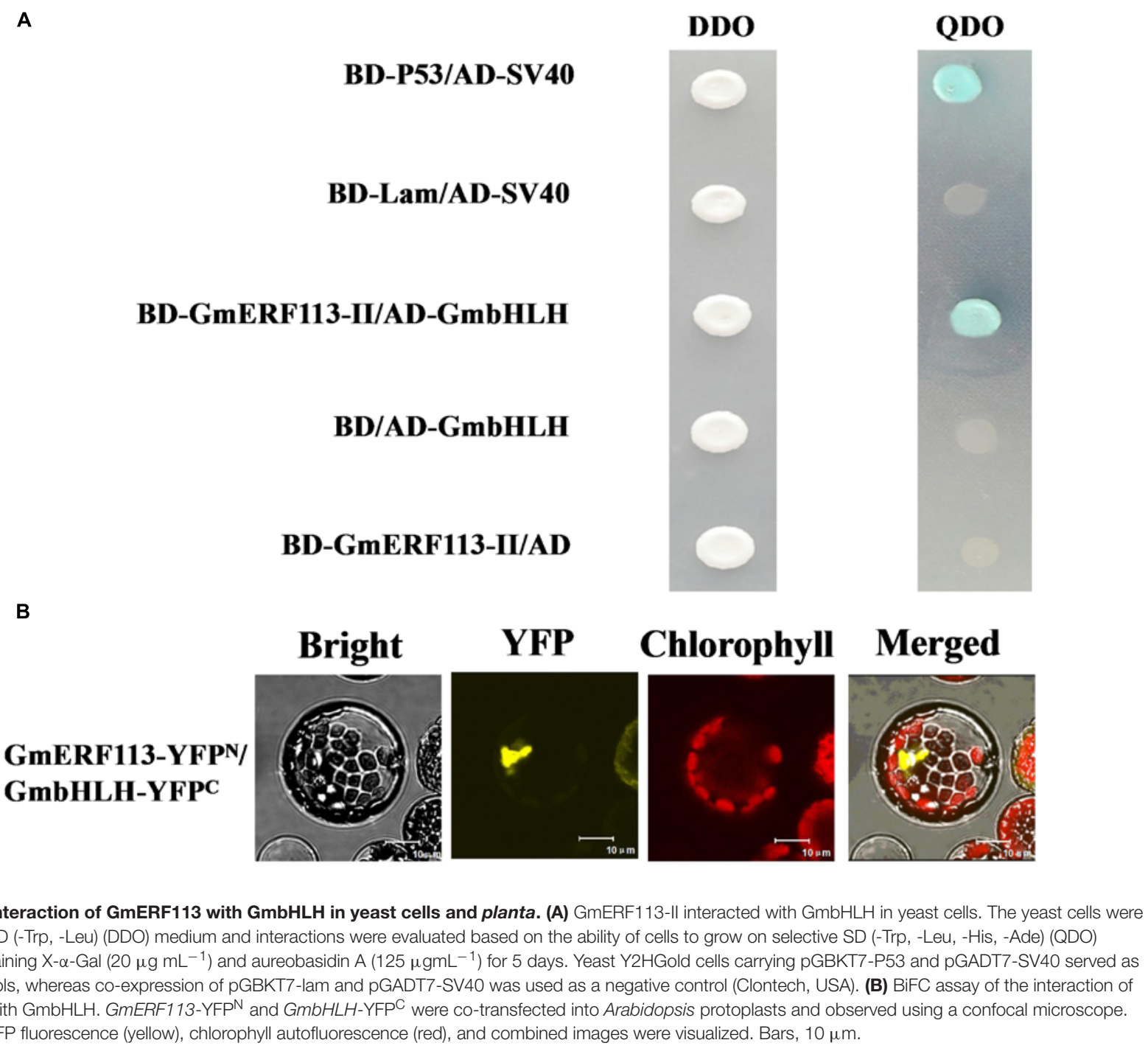

genes (GmbHLH, GmPRP, GmHAT5, and GmFAO), with predicted functions related to pathogenesis and disease resistance, were selected for further investigation. Full-length cDNAs of these four genes were cloned and constructed in pGADT7. Analysis of whether these proteins had transcription activation and interaction with GmERF113 in yeast cells was performed. Our results showed that the four proteins could not activate transcription in yeast cells, and only GmbHLH interacted with GmERF113-II (Figure 6A), while the other three candidate proteins could not interact with GmERF113-II in yeast.

To further confirm the interaction of GmERF113 with the candidate proteins, a BiFC assay was carried out using the Arabidopsis protoplast transient expression system in planta. Obvious fluorescence was detected in the chloroplasts derived from Arabidopsis protoplasts cells after co-transformation of both N-terminal yellow fluorescent protein $\left(\mathrm{YFP}^{\mathrm{N}}\right)$-tagged GmERF113 and C-terminal YFP (YFPC)-tagged GmbHLH (Figure 6B). However, no fluorescence was detected in
Arabidopsis protoplast cells co-transformed with $\mathrm{YFP}^{\mathrm{N}}$ GmERF113 and YFP - GmPRP or $\mathrm{YFP}^{\mathrm{N}}-\mathrm{GmERF}_{113}$ and $\mathrm{YFP}^{\mathrm{C}}$-GmHAT5 or YFP ${ }^{\mathrm{N}}-\mathrm{GmERF} 113$ and YFP $\mathrm{C}_{-\mathrm{GmFAO}}$ (data not shown). These results indicated that the GmERF113 protein and GmbHLH protein physically interacted in plana.

\section{Increased Expression of PR Genes in GmERF113 Transgenic Soybean}

To investigate whether GmERF113 could activate expression of downstream PR genes, the levels of GmERF113 and two PR genes were analyzed in 35S:GmERF113 transgenic and non-transgenic soybean plants by qRT-PCR. As shown in Figure 7, expression levels of GmERF113 in the three transgenic plants (G1-G3) were at least twice more than that of the control. Expression levels of GmPR1 and GmPR10-1, which contained a GCC-box in their promoters, were also greatly increased in GmERF113 transgenic soybean plants, with a maximum fold-change relative to wild-type of 73 times, but barely detected in non-transgenic plants. These results indicated that the expression of GmPR1 and 


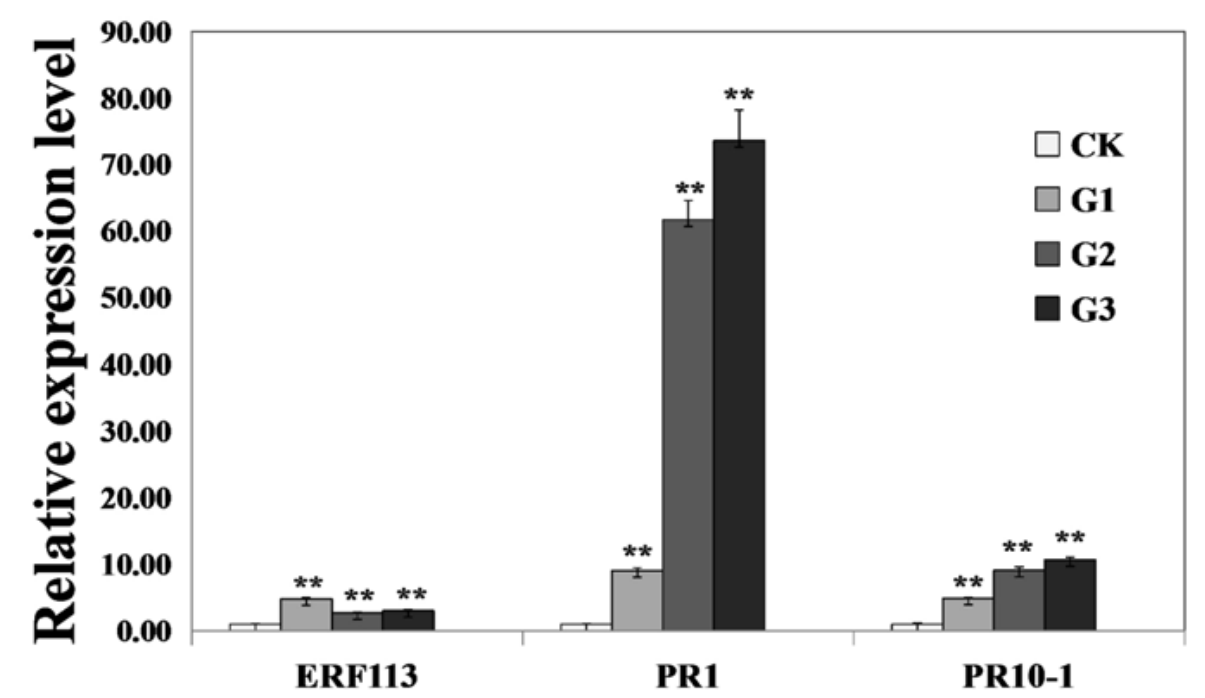

FIGURE 7 | Analysis of the expression of GmERF113 and two PR genes in wild-type and 35S:GmERF113 transgenic soybean plants. Relative transcript abundance of GmERF113, GmPR1 (XM_003545722), and GmPR10-1 (NM_001251335) in three transgenic lines (G1-G3) was compared with that in wild-type soybean plants. All data were normalized to levels of amplified soybean GmEF1 $\beta$. Statistically significant differences between the GmERF113 overexpressing transgenic lines and wild type $(\mathrm{CK})$ plants were evaluated. Three technical replicates were averaged and statistically analyzed using Student's $t$-tests (** $P<0.01)$. Bars indicate standard error of the mean (SE).

GmPR10-1 was upregulated in GmERF113 transgenic soybean plants.

\section{Overexpression of GmERF113 in Soybean Enhances Resistance to P. sojae}

To determine whether overexpression of GmERF113 can improve resistance to $P$. sojae in transgenic soybean plants, $\mathrm{T}_{1}$ and $\mathrm{T}_{2}$ transgenic plants, screened by PCR amplification and Southern hybridization, were used to generate $\mathrm{T}_{3}$ plants, constituting three independent GmERF113-overexpressing transgenic lines. The overexpression of GmERF113 in the $\mathrm{T}_{3}$ transgenic soybean lines (G1, G2, and G3) was detected by qRT-PCR to investigate the response of the plants to $P$. sojae (Figure 8A). Four days after inoculation with $P$. sojae, the leaves of non-transgenic soybean plants showed clear, large lesions compared with those of transgenic soybean plants (Figure 8B); the lesion areas in transgenic soybean lines were significantly smaller than those in non-transgenic plants $(P<0.01)$ (Figure 8C).

Furthermore, $\mathrm{T}_{4}$ transgenic soybean plants (G1-1, G2-1, and G3-1) were identified by qRT-PCR (Figure 8D) and the relative biomass of $P$. sojae in infected live cotyledons after $48 \mathrm{~h}$ incubation with $P$. sojae zoospore suspensions was tested. As shown in Figure $8 \mathrm{E}$, after $48 \mathrm{~h}$ of incubation with $P$. sojae, the cotyledons of transgenic soybean plants exhibited smaller lesions compared with those of non-transgenic plants. The biomass of $P$. sojae, based on the transcript levels of the P. sojae TEF1 gene, was significantly lower in transgenic GmERF113-overexpressing plants than that in non-transgenics $(P<0.01)$ (Figure $8 \mathbf{F}$ ). These findings demonstrated that overexpression of GmERF113 in soybean plants increased their resistance to $P$. sojae.

\section{DISCUSSION}

In this study, GmERF113, a new member of the ERF subfamily identified in soybean, was demonstrated to increase soybean resistance to $P$. sojae. ERF transcription factors have been identified in numerous plant species, including Arabidopsis thaliana (Liu et al., 1998; Nakano et al., 2006; Son et al., 2012), rice (Cao et al., 2006; Zhang et al., 2013), wheat (Xu et al., 2007), cotton (Huang et al., 2007; Jin and Liu, 2008), tomato (Sharma et al., 2010), cucumber (Hu and Liu, 2011), tobacco (Fischer and Droge-Laser, 2004), Chinese wild grapevine (Zhu et al., 2013), and peanut (Wan et al., 2014), among others. To our knowledge, only six members of the ERF subfamily have been functionally characterized in soybean (Mazarei et al., 2002; Zhang et al., 2008, 2009; Zhang G.Y. et al., 2010; Zhai et al., 2013a,b; Dong et al., 2015). Among these, GmEREBP1 is assigned to the B-3 subgroup (Mazarei et al., 2002), while GmERF3 and GmERF7 (Zhang et al., 2009; Zhai et al., 2013b) are in the B-2 subgroup. These ERF proteins act as transcriptional activators and increase salt stress tolerance in tobacco. GmERF4, GmERF5, and GmERF6 are assigned to the B-1 subgroup, and contain EAR motifs, which are characteristic of ERF repressors, and can repress negative regulators of plant defense responses; thereby, constitutive expression of GmERF4 in transgenic tobacco plants increases tolerance to salt and drought stress (Zhang G.Y. et al., 2010), overexpression of GmERF6 in transgenic Arabidopsis enhances resistance to drought stress (Zhai et al., 2013a), and overexpression of GmERF5 in tobacco and soybean plants improves resistance to $P$. nicotianae and $P$. sojae, respectively (Dong et al., 2015). There are three Arabidopsis ERFs in the B-4 subgroup, ABR1, AtRAP2.6L, and AtRAP2.6, which have been reported to respond to various biotic and abiotic stresses 
A

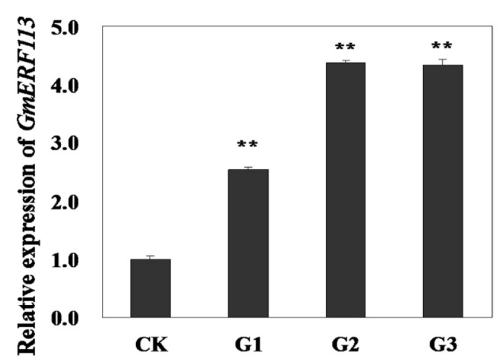

B

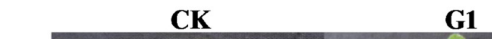

G1
C

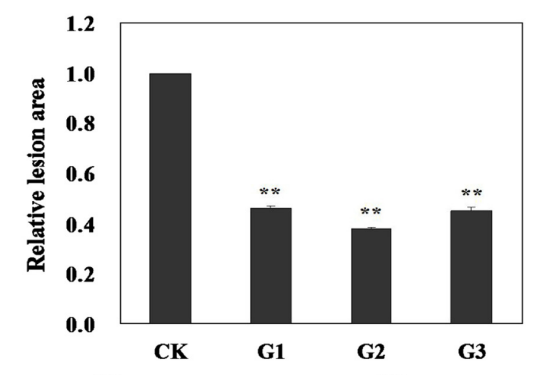

2d

G3

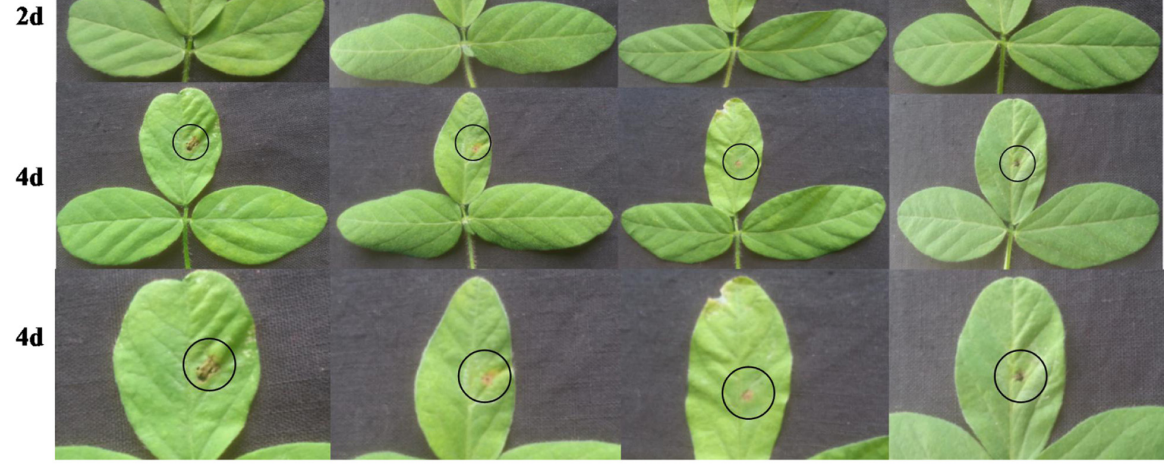

D

$\mathbf{F}$
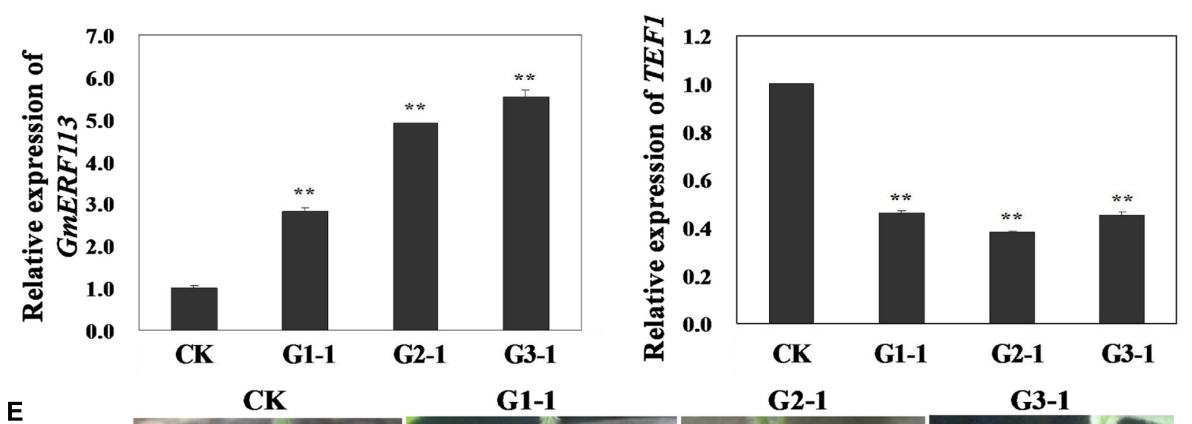

E
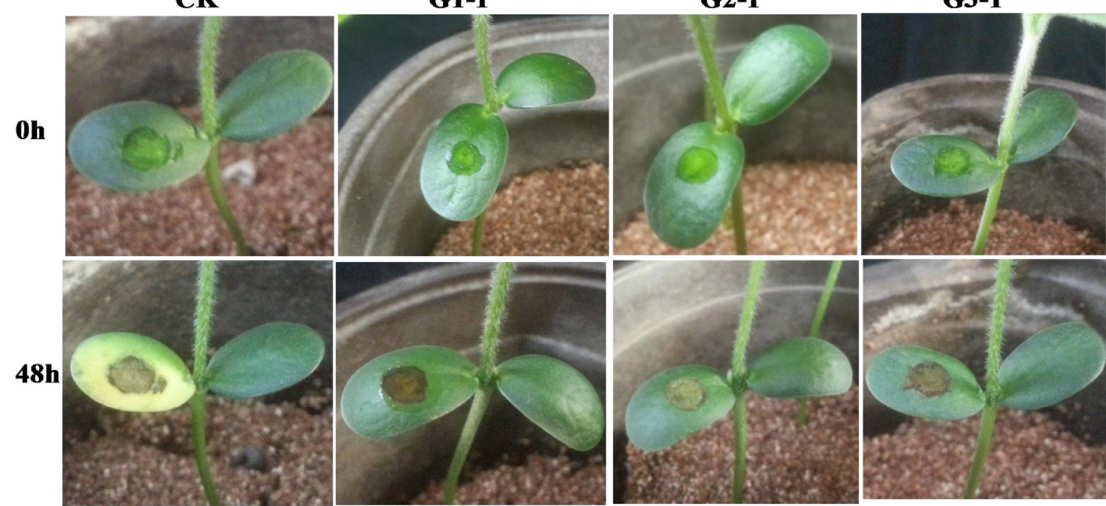

FIGURE 8 | Responses of living of GmERF113 transgenic soybean plants to P. sojae. (A) Quantitative real-time PCR (qRT-PCR) analysis of GmERF113 expression levels in $T_{3}$ transgenic soybean plants. (B) Disease symptoms on the leaves of $T_{3}$ transgenic and non-transgenic lines infected with $P$. sojae race 1 inoculum at 2 and 4 days. (C) The lesion areas of the transgenic and non-transgenic lines were determined 4 days after inoculation with P. sojae. (D) qRT-PCR analysis of GmERF113 expression levels in $\mathrm{T}_{4}$ transgenic soybean plants. (E) Disease symptoms on the cotyledons of $\mathrm{T}_{4}$ transgenic and non-transgenic lines $48 \mathrm{~h}$ after treatment with $P$. sojae zoospore suspension. (F) qRT-PCR analysis of $P$. sojae relative biomass based on the transcript level of the $P$. sojae TEF1 gene in infected cotyledons $48 \mathrm{~h}$ after incubation with $P$. sojae zoospore suspension. The experiment was performed using three biological replicates with three technical replicates each and statistically analyzed using Student's $t$-tests $(* * P<0.01)$. Bars indicate standard error of the mean (SE). 


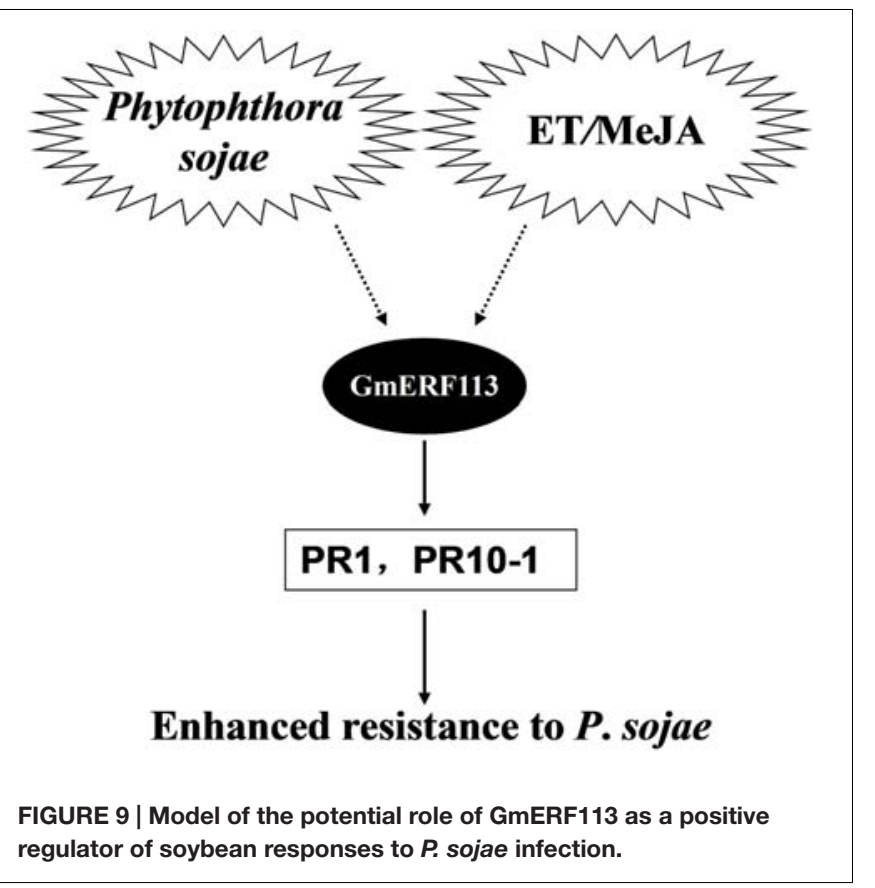

(Asahina et al., 2011; Choi and Hwang, 2011; Ali et al., 2013). As the only known soybean ERF transcription factor in the B-4 subgroup, GmERF113 may positively regulate the expression of PR genes and enhance resistance to $P$. sojae in soybean.

Similar to other ERF proteins, GmERF113 has alanine and aspartic acid at positions 14 and 19 of the 58-AA AP2/ERF domain, suggesting that it is a member of the ERF subfamily. Sequence analysis revealed that GmERF113 has a basic AA region $\left(\mathrm{R}_{45} \mathrm{KRH}\right)$ toward its $\mathrm{N}$-terminus which may function as a nuclear localization signal and our results demonstrate that the protein does indeed localize to the nucleus.

Using EMSAs, we verified the ability of GmERF113 to bind to GCC-box; however, the band-shift signal obtained was very weak, possibly due the in vitro experimental conditions being sub-optimal for protein/DNA interaction. Two specific shifted bands were observed in EMSAs, and large amounts of additional non-radioactively labeled probe was required to effectively compete with the labeled probe. The results of yeast onehybrid assays, demonstrating that the GmERF113 protein bound specifically to the GCC-box, were more persuasive. Furthermore, a transcription activation assay showed that GmERF113 could activate GCC-box-mediated transcription. These findings suggest that GmERF113 may act as a transcriptional activator through interaction with GCC-box motifs.

Ethylene response factor subfamily genes have crucial roles in the responses of plants to biotic stress (Okamuro et al., 1997; Singh et al., 2002; Cao et al., 2006; Barah et al., 2013): overexpression of soybean GmERF3 in transgenic tobacco led to increased resistance to Ralstonia solanacearum, Alternaria alternata, and TMV (Zhang et al., 2009); of AtERF6 in Arabidopsis enhanced resistance to the fungal pathogen, Botrytis cinerea (Moffat et al., 2012); and of RAP2.6 enhanced resistance against the beet cyst nematode, Heterodera schachtii, in Arabidopsis roots
(Ali et al., 2013). In the present study, we demonstrated that overexpression of GmERF113 increased soybean resistance to P. sojae.

Ethylene response factors regulate the expression of ETinducible PR genes containing GCC-box sequences in their promoter regions (Ohme-Takagi and Shinshi, 1995). For example, GmERF3 can bind to the GCC-box, and overexpression of $G m E R F 3$ in transgenic tobacco activates the expression of several PR genes, including PR1, PR2, and PR4 (Zhang et al., 2009). Our results demonstrating significantly increased transcript levels of GmPR1 and GmPR10-1 in GmERF113 transgenic soybean plants (Figure 7) are consistent with these published data. Our previous research confirmed that transgenic soybean plants over-expressing GmPR10 had increased resistance to P. sojae (Jiang et al., 2015). We speculated that GmPR1 and GmPR10-1 could be direct or indirect targets of GmERF113 and the results presented here prove that GmERF113 can positively regulate the expression of $\mathrm{PR}$ genes, thus improving soybean resistance to $P$. sojae.

Some ERFs are involved in the regulation of gene expression through interactions with other proteins or transcription factors ( $\mathrm{Gu}$ et al., 2000; Xu et al., 2011). For example, the AP2/ERF factor, NtORC1, interacts with NtbHLH and commonly regulates the expression of genes containing G-box and GCC motifs in their promoter regions (De Boer et al., 2011). A transcriptional repressor recently identified in banana fruit, MaERF10, interacts with MaJAZ3 proteins to enforce the repression of jasmonate (JA) biosynthesis-related genes involved in MeJA-mediated cold tolerance (Qi et al., 2016). In the present study, GmbHLH was found to interact with GmERF113 using yeast two-hybrid and BiFC assays. Some bHLH proteins participate in regulation of PR gene expression (Abe et al., 1997; Friedrichsen et al., 2002); for example, the bHLH transcription factor, AtHBI1, mediates pathogen-associated molecular patterntriggered immunity in A. thaliana (Fan et al., 2014). We therefore speculate that GmERF113 and GmbHLH proteins may cooperatively regulate resistance to $P$. sojae infection. Our previous research demonstrated that GmERF5, acting as a GCC-mediated transcriptional repressor, also interacted with GmbHLH and that overexpression of GmERF5 could improve soybean resistance to $P$. sojae (Dong et al., 2015). Thus, we hypothesize that GmbHLH may play a crucial role in modulating EFR transcription factors in defense against $P$. sojae infection.

The phytohormones ET, JA, SA, and ABA are important for the regulation of defense responses in plants (Zhou et al., 1997; Pieterse et al., 2009; Seo et al., 2011; Zhu et al., 2013). Plant stresstolerance is regulated through a network of signal transduction pathways, some of which may converge on ERF proteins through complex interactions (Zhang et al., 2004; Rehman and Mahmood, 2015). For example, AtERF4 is thought to be a key factor in the regulation of ET/ABA-dependent defense pathways and could modulate the transcription of many ET/ABA-dependent defense genes (Yang et al., 2005); GmERF3 may connect the ET, JA, and SA signaling pathways, which mediate biotic and abiotic stress responses (Zhang et al., 2009); Dong (2001) determined that two well-defined signaling pathways involved in pathogendefense responses make use of the plant hormones SA or ET/JA, 
respectively; Kamsvågmagnusson et al. (2014) also reported that the expression of genes encoding ERFs is regulated in both an ET-dependent and -independent manner; while jasmonates (JAs) also play central signaling roles, using MeJA as an elicitor, in a wide range of plant resistance responses (Thagun et al., 2016). Our present study demonstrated that levels of GmERF113 mRNA transcripts were significantly enhanced by $P$. sojae, ET, and MeJA stress; however, the observed changes elicited in response to $\mathrm{SA}$ and $\mathrm{ABA}$ stress were relatively minor. We deduce that GmERF113 may depend primarily on ET and MeJA signaling pathways, which mediate soybean responses to $P$. sojae infection.

Based on our data, we propose a model to explain the potential role of GmERF113 as a positive regulator of soybean responses to P. sojae infection (Figure 9). Expression of the GmERF113 gene is activated by $P$. sojae infection, while exogenous ET and MeJA also induce moderate accumulation of GmERF113 mRNA. GmERF113 is involved in the integration of signals to activate the expression of $\mathrm{PR}$ genes through binding to GCC-box motifs, and thereby enhances soybean resistance to P. sojae. Meanwhile, GmERF113 and GmbHLH may interact to cooperatively regulate the $P$. sojae resistance response. As members of the same subfamily, GmERF5 and GmERF113 have similar functions, as described above. Furthermore, expression of GmERF5 is significantly induced by ABA and SA, suggesting that this protein may be involved in ABA-mediated salt and drought tolerance. GmERF5 is the soybean EAR motif-containing ERF transcription repressor demonstrated as involved in the response to pathogen infection (Dong et al., 2015), while GmERF113 is the soybean ERF transcription activator with a crucial role in the

\section{REFERENCES}

Abe, H., Yamaguchi-Shinozaki, K., Urao, T., Iwasaki, T., Hosokawa, D., and Shinozaki, K. (1997). Role of Arabidopsis MYC and MYB homologs in droughtand abscisic acid-regulated gene expression. Plant Cell 9, 1859-1868. doi: 10. 2307/3870530

Ali, M. A., Abbas, A., Kreil, D. P., and Bohlmann, H. (2013). Overexpression of the transcription factor RAP2.6 leads to enhanced callose deposition in syncytia and enhanced resistance against the beet cyst nematode Heterodera schachtii in Arabidopsis roots. BMC Plant Biol. 13:47. doi: 10.1186/1471-2229-13-47

Asahina, M., Azuma, K., Pitaksaringkarn, W., Yamazaki, T., Mitsuda, N., OhmeTakagi, M., et al. (2011). Spatially selective hormonal control of RAP2.6L and ANAC071 transcription factors involved in tissue reunion in Arabidopsis. Proc. Natl. Acad. Sci. U.S.A. 108, 16128-16132. doi: 10.1073/pnas.1110443108

Bailey, K. L., Gossen, B. D., Gugel, R. K., and Morrall, R. A. A. (2003). Diseases of Field Crops in Canada. Saskatoon, SK: Canadian Phytopathological Society, 155-156.

Barah, P., Winge, P., Kusnierczyk, A., Tran, D. H., and Bones, A. M. (2013). Molecular signatures in Arabidopsis thaliana in response to insect attack and bacterial infection. PLOS ONE 8:e58987. doi: 10.1371/journal.pone. 0058987

Berrocallobo, M., Molina, A., and Solano, R. (2002). Constitutive expression of ETHYLENE-RESPONSE-FACTOR1 in Arabidopsis confers resistance to several necrotrophic fungi. Plant J. 29, 23-32. doi: 10.1046/j.1365-313x.2002. 01191.x

Bui, L. T., Giuntoli, B., Kosmacz, M., Parlanti, S., and Licausi, F. (2015). Constitutively expressed ERF-VII transcription factors redundantly activate the core anaerobic response in Arabidopsis thaliana. Plant Sci. 236, 37-43. doi: $10.1016 /$ j.plantsci.2015.03.008

Cao, Y., Song, F., Goodman, R. M., and Zheng, Z. (2006). Molecular characterization of four rice genes encoding ethylene-responsive transcriptional defense of soybean against $P$. sojae infection. This study provides new insights into the mechanism by which the GmERF113 protein regulates biotic stress responses in soybean.

\section{AUTHOR CONTRIBUTIONS}

Conceived and designed the experiments: PX and SZ. Performed the experiments and drafted the manuscript: YZ, XCha, LJ, LD, and QC. Analyzed the data: SF, GW, XChe, DH, and DQ. Contributed reagents/materials/analysis tools: SZ and PX.

\section{FUNDING}

This work was supported by NSFC Projects (31171577, 31671719), Natural Science Foundation of Heilongjiang Province (JC201308, C2015010), Changjiang Scholar Candidates Program for Provincial Universities in Heilongjiang (2013CJHB003), the Science and Technology Innovation Project in NEAU (14QC25) and Outstanding Talents and Innovative Team of Agricultural Scientific Research.

\section{SUPPLEMENTARY MATERIAL}

The Supplementary Material for this article can be found online at: http://journal.frontiersin.org/article/10.3389/fpls.2017.00299/ full\#supplementary-material

factors and their expressions in response to biotic and abiotic stress. J. Plant Physiol. 163, 1167-1178. doi: 10.1016/j.jplph.2005.11.004

Chacón, O., González, M., López, Y., Portieles, R., Pujol, M., González, E., et al. (2010). Over-expression of a protein kinase gene enhances the defense of tobacco against Rhizoctonia solani. Gene 452, 54-62. doi: 10.1016/j.gene.2009. 11.011

Chen, S. B., Songkumarn, P., Liu, J. L., and Wang, G. L. (2009). A versatile zero background T-vector system for gene cloning and functional genomics. Plant Physiol. 150, 1111-1121. doi: 10.1104/pp.109.137125

Chen, S. B., Tao, L. Z., Zeng, L. R., Vega-Sanchez, M. E., Umemura, K., and Wang, G. L. (2006). A highly efficient transient protoplast system for analyzing defence gene expression and protein-protein interactions in rice. Mol. Plant Pathol. 7, 417-427. doi: 10.1111/J.1364-3703.2006.00346.X

Cheong, Y. H., Moon, B. C., Kim, J. K., Kim, C. Y., Kim, M. C., Kim, I. H., et al. (2003). BWMK1, a rice mitogen-activated protein kinase, locates in the nucleus and mediates pathogenesis-related gene expression by activation of a transcription factor. Plant Physiol. 132, 1961-1972. doi: 10.1104/pp.103.023176

Choi, D. S., and Hwang, B. K. (2011). Proteomics and functional analyses of pepper abscisic acid-responsive 1 (ABR1), which is involved in cell death and defense signaling. Plant Cell 23, 823-842. doi: 10.1105/tpc.110.082081

De Boer, K., Tilleman, S., Pauwels, L., Vanden Bossche, R., De Sutter, V., Vanderhaeghen, R., et al. (2011). APETALA2/ETHYLENE response factor and basic helix-loop-helix tobacco transcription factors cooperatively mediate jasmonate-elicited nicotine biosynthesis. Plant J. 66, 1053-1065. doi: 10.1111/j. 1365-313X.2011.04566.x

Dong, L. D., Cheng, Y. X., Wu, J. J., Cheng, Q., Li, W. B., Fan, S. J., et al. (2015). Overexpression of GmERF5, a new member of the soybean EAR motifcontaining ERF transcription factor, enhances resistance to Phytophthora sojae in soybean. J. Exp. Bot. 66, 2635-2647. doi: 10.1093/jxb/erv078

Dong, X. (2001). Genetic dissection of systemic acquired resistance. Curr. Opin. Plant Biol. 4, 309-314. doi: 10.1016/S1369-5266(00)00178-3 
Fan, M., Bai, M. Y., Kim, J. G., Wang, T., Oh, E., Chen, L., et al. (2014). The bHLH transcription factor HBI1 mediates the trade-off between growth and pathogenassociated molecular pattern-triggered immunity in Arabidopsis. Plant Cell 26, 828-841. doi: 10.1105/tpc.113.121111

Fehr, W. R., Caviness, C. E., Burmood, D. T., and Pennington, J. S. (1971). Stage of development descriptions for soybeans, Glycine max (L.) Merrill. Crop Sci. 11, 929-931. doi: 10.2135/cropsci1971.0011183X001100060051x

Fischer, U., and Droge-Laser, W. (2004). Overexpression of NtERF5, a new member of the tobacco ethylene response transcription factor family enhances resistance to tobacco mosaic virus. Mol. Plant Microbe Interact. 17, 1162-1171. doi: 10.1094/MPMI.2004.17.10.1162

Friedrichsen, D. M., Nemhauser, J., Muramitsu, T., Maloof, J. N., Alonso, J., Ecker, J. R., et al. (2002). Three redundant brassinosteroid early response genes encode putative bHLH transcription factors required for normal growth. Genetics 162, 1445-1456.

Fujimoto, S. Y., Ohta, M., Usui, A., Shinshi, H., and Ohme-Takagi, M. (2000). Arabidopsis ethylene-responsive element binding factors act as transcriptional activators or repressors of GCC box-mediated gene expression. Plant Cell 12, 393-404. doi: 10.2307/3870944

Gu, Y. Q., Yang, C., Thara, V. K., Zhou, J., and Martin, G. B. (2000). Pti4 is induced by ethylene and salicylic acid and its product is phosphorylated by the Pto kinase. Plant Cell 12, 771-786. doi: 10.2307/3871000

Hao, D. Y., Ohme-Takagi, M., and Sarai, A. (1998). Unique mode of GCC box recognition by the DNA-binding domain of ethylene-responsive elementbinding factor (ERF domain) in plants. J. Biol. Chem. 273, 26857-26861. doi: $10.1074 /$ jbc. 273.41 .26857

Holsters, M., De, W. D., Depicker, A., Messens, E., Van, M. M., and Schell, J. (1978). Transfection and transformation of Agrobacterium tumefaciens. Mol. Genet. Genomics 163, 181-187. doi: 10.1007/BF00267408

Hu, L. F., and Liu, S. Q. (2011). Genome-wide identification and phylogenetic analysis of the ERF gene family in cucumbers. Genet. Mol. Biol. 34, 624-633. doi: 10.1590/S1415-47572011005000054

Huang, B., Jin, L. G., and Liu, J. Y. (2007). Molecular cloning and functional characterization of a DREB1/CBF-like gene (GhDREB1L) from cotton. Sci. China Life Sci. 50, 7-14. doi: 10.1007/s11427-007-0010-8

Jiang, L. Y., Wu, J. J., Fan, S. J., Li, W. B., Dong, L. D., and Cheng, Q. (2015). Isolation and characterization of a novel pathogenesis-related protein gene (GmPRP) with induced expression in soybean (Glycine max) during infection with Phytophthora sojae. PLoS ONE 10:e0129932. doi: 10.1371/journal.pone. 0129932

Jin, L. G., and Liu, J. Y. (2008). Molecular cloning, expression profile and promoteranalysis of a novel ethylene responsive transcription factor gene GhERF4 from cotton (Gossypium hirstum). Plant Physiol. Biochem. 46, 46-53. doi: $10.1016 /$ j.plaphy.2007.10.004

Kamsvågmagnusson, T., Thorsellcederberg, J., Svanberg, A., Von, E. L., Arvidson, J., Mellgren, K., et al. (2014). Role of ethylene response transcription factor (ERF) and its regulation in response to stress encountered by plants. Plant Mol. Biol. Rep. 33, 1-11. doi: 10.1007/s11105-014-0799-9

Kim, Y. J., Jang, M. G., Lee, H. J., Jang, G. H., Sukweenadhi, J., Kwon, W. S., et al. (2014). Functional characterization of the pathogenesis-related protein family 10 gene, PgPR10-4, from Panax ginseng in response to environmental stresses. Plant Cell Tiss. Org. 118, 531-543. doi: 10.1007/s11240-014-0505-5

Koyama, T., Okada, T., Kitajima, S., Ohme-Takagi, M., Shinshi, H., and Sato, F. (2003). Isolation of tobacco ubiquitin-conjugating enzyme cDNA in a yeast two-hybrid system with tobacco ERF3 as bait and its characterization of specific interaction. J. Exp. Bot. 54, 1175-1181. doi: 10.1093/jxb/erg136

Lai, Y., Dang, F. F., Lin, J., Yu, L., Shi, Y. L., Xiao, Y., et al. (2013). Overexpression of a Chinese cabbage BrERF11 transcription factor enhances disease resistance to Ralstonia solanacearum in tobacco. Plant Physiol. Biochem. 62, 70-78. doi: 10.1016/j.plaphy.2012.10.010

Li, Z. F., Zhang, L. X., Yu, Y. W., Quan, R. D., Zhang, Z. J., Zhang, H. W., et al. (2011). The ethylene response factor AtERF11 that is transcriptionally modulated by the bZIP transcription factor HY5 is a crucial repressor for ethylene biosynthesis in Arabidopsis. Plant J. 68, 88-99. doi: 10.1111/j.1365313X.2011.04670.x

Liang, H. X., Lu, Y., Liu, H. X., Wang, F. D., Xin, Z. Y., and Zhang, Z. Y. (2008). A novel activator type ERF of Thinopyrum intermedium, TiERF1, positively regulates defence responses. J. Exp. Bot. 59, 3111-3120. doi: 10.1093/jxb/ern 165
Liu, Q., Kasuga, M., Sakuma, Y., Abe, H., Miura, S., Yamaguchi-Shinozaki, K., et al. (1998). Two transcription factors, DREB1 and DREB2, with an EREBP/AP2 DNA binding domain, separate two cellular signal transduction pathways in drought and low temperature responsive gene expression, respectively, in Arabidopsis. Plant Cell 10, 1391-1406. doi: 10.1105/tpc.10.8.1391

Liu, Y., Zhao, T. J., Liu, J. M., Liu, W. Q., Liu, Q., Yan, Y. B., et al. (2006). The conserved Ala37 in the ERF/AP2 domain is essential for binding with the DRE element and the GCC box. FEBS Lett. 580, 1303-1308. doi: 10.1016/j.febslet. 2006.01.048

Lorenzo, O., Piqueras, R., Sanchez-Serrano, J. J., and Solano, R. (2003). Ethylene response factor 1 integrates signals from ethylene and jasmonate pathways in plant defense. Plant Cell 15, 165-178. doi: 10.1105/tpc.007468

Maruyama, Y., Yamoto, N., Suzuki, Y., Chiba, Y., Yamazaki, K., Sato, T., et al. (2013). The Arabidopsis transcriptional repressor ERF9 participates in resistance against necrotrophic fungi. Plant Sci. 213, 79-87. doi: 10.1016/j. plantsci.2013.08.008

Mazarei, M., Puthoff, D. P., Hart, J. K., Rodermel, S. R., and Baum, T. J. (2002). Identification and characterization of a soybean ethylene responsive element binding protein gene whose mRNA expression changes during soybean cyst nematode infection. Mol. Plant Microbe Interact. 15, 577-586. doi: 10.1094/ MPMI.2002.15.6.577

Moffat, C. S., Ingle, R. A., Wathugala, D. L., Saunders, N. J., Knight, H., and Knight, M. R. (2012). ERF5 and ERF6 play redundant roles as positive regulators of JA/Et-mediated defense against Botrytis cinerea in Arabidopsis. PLoS ONE 7:e35995. doi: 10.1371/journal.pone.0035995

Morris, P. F., Savard, M. E., and Ward, E. W. B. (1991). Identification and accumulation of isoflavonoids and isoflavone glucosides in soybean leaves and hypocotyls in resistance responses to Phytophthora megasperma f. sp. glycinea. Physiol. Mol. Plant Pathol. 39, 229-244. doi: 10.1016/0885-5765(91)90006-4

Nakano, T., Suzuki, K., Fujimura, T., and Shinshi, H. (2006). Genome-wide analysis of the ERF gene family in Arabidopsis and rice. Plant Physiol. 140, 411-432. doi: 10.1104/pp.105.073783

Ohme-Takagi, M., and Shinshi, H. (1995). Ethylene-inducible DNA binding proteins that interact with an ethylene-responsive element. Plant Cell 7, 173-182. doi: 10.1105/tpc.7.2.173

Okamuro, J. K., Caster, B., Villarroel, R., Montagu, M. V., and Jofuku, K. D. (1997). The AP2 domain of APETALA2 defines a large new family of DNA binding proteins in Arabidopsis. Proc. Natl. Acad. Sci. U.S.A. 94, 7076-7081. doi: 10.1073/pnas.94.13.7076

Paz, M. M., Shou, H., Guo, Z., Zhang, Z., Banerjee, A. K., and Wang, K. (2004). Assessment of conditions affecting Agrobacterium-mediated soybean transformation using the cotyledonary node explants. Euphytica 136, 167-179. doi: 10.1023/B:EUPH.0000030669.75809.dc

Pieterse, C. M. J., Leon-Reyes, A., Vander, E. S., and Van, W. S. (2009). Networking by small- molecule hormones in plant immunity. Nat. Chem. Biol. 5, 308-316. doi: $10.1038 /$ nchembio.164

Qi, X. N., Xiao, Y. Y., Fan, Z. Q., Chen, J. Y., Lu, W. J., and Kuang, J. F. (2016). A banana fruit transcriptional repressor MaERF10 interacts with MaJAZ3 to strengthen the repression of JA biosynthetic genes involved in MeJAmediated cold tolerance. Postharvest Biol. Technol. 120, 222-231. doi: 10.1016/ j.postharvbio.2016.07.001

Qiu, Z. G., Xu, Z. S., Zheng, T. H., Li, L. C., Chen, M., and Ma, Y. Z. (2011). Screening and identi?cation of proteins interacting with ERF transcription factor W17 in wheat. Acta Agron. Sin. 37, 1-8. doi: 10.3724/SP.J.1006.2011. 00803

Rehman, S., and Mahmood, T. (2015). Functional role of DREB and ERF transcription factors: regulating stress-responsive network in plants. Acta Physiol. Plant. 37, 1-14. doi: 10.1007/s11738-015-1929-1

Sakuma, Y., Liu, Q., Dubouzet, J. G., Abe, H., Shinozaki, K., and YamaguchiShinozaki, K. (2002). DNA-binding specificity of the ERF/AP2 domain of Arabidopsis DREBs, transcription factors involved in dehydration and coldinducible gene expression. Biochem. Biophys. Res. Commun. 290, 998-1009. doi: 10.1006/bbrc.2001.6299

Schwechheimer, C., and Bevan, M. (1998). The regulation of transcription factor activity in plants. Trends Plant Sci. 3, 378-383. doi: 10.1016/S1360-1385(98) 01302-8

Seo, J. S., Joo, J., Kim, M. J., Kim, Y. K., Nahm, B. H., Song, S. I., et al. (2011). OsbHLH148, a basic helix-loop-helix protein, interacts with OsJAZ proteins in 
a jasmonate signaling pathway leading to drought tolerance in rice. Plant J. 65, 907-921. doi: 10.1111/j.1365-313X.2010.04477.x

Sharma, M. K., Kumar, R., Solanke, A. U., Sharma, R., Tyagi, A. K., and Sharma, A. K. (2010). Identification, phylogeny, and transcript profiling of ERF family genes during development and abiotic stress treatments in tomato. Mol. Genet. Genomics 284, 455-475. doi: 10.1007/s00438-0100580-1

Shinozaki, K., Yamaguchi-Shinozaki, K., and Seki, M. (2003). Regulatory network of gene expression in the drought and cold stress responses. Cur. Opin. Plant Biol. 6, 410-417. doi: 10.1016/S1369-5266(03)00092-X

Singh, K. B., Foley, R. C., and Onate-Sanchez, L. (2002). Transcription factors in plant defense and stress responses. Curr. Opin. Plant Biol. 5, 430-436. doi: 10.1016/S1369-5266(02)00289-3

Son, G. H., Wan, J., Kim, H. J., Nguyen, X. C., Chung, W. S., Hong, J. C., et al. (2012). Ethylene-responsive element-binding factor 5, ERF5, is involved in chitin-induced innate immunity response. Mol. Plant Microbe Interact. 25, 48-60. doi: 10.1094/MPMI-06-11-0165

Song, C. P., Agarwal, M., Ohta, M., Guo, Y., Halfter, U., Wang, P. C., et al. (2005). Role of an Arabidopsis AP2/EREBP-type transcriptional repressor in abscisic acid and drought stress responses. Plant Cell 17, 2384-2396. doi: 10.1105/tpc. 105.033043

Sugano, S., Sugimoto, T., Takatsuji, H., and Jianga, C. J. (2013). Induction of resistance to Phytophthora sojae in soybean (Glycine max) by salicylic acid and ethylene. Plant Pathol. 62, 1048-1056. doi: 10.1111/ppa.12011

Thagun, C., Imanishi, S., Kudo, T., Nakabayashi, R., Ohyama, K., Mori, T., et al. (2016). Jasmonate-responsive ERF transcription factors regulate steroidal glycoalkaloid biosynthesis in tomato. Plant Cell Physiol. 57, 961-975. doi: $10.1093 /$ pcp/pcw067

Thomashow, M. F. (1999). Plant cold acclimation: freezing tolerance genes and regulatory mechanism. Annu. Rev. Plant Biol. 50, 571-599. doi: 10.1146/ annurev.arplant.50.1.571

Tyler, B. M. (2007). Phytophthora sojae: root rot pathogen of soybean and model oomycete. Mol. Plant Pathol. 8, 1-8. doi: 10.1111/j.1364-3703.2006. 00373.x

Wan, L. Y., Wu, Y. S., Huang, J. Q., Dai, X. F., Lei, Y., Yan, L. Y., et al. (2014). Identification of ERF genes in peanuts and functional analysis of AhERF008 and AhERF019 in abiotic stress response. Funct. Integr. Genomic. 14, 467-477. doi: 10.1007/s10142-014-0381-4

Ward, E. W. B., Lazarovits, G., Unwin, C. H., and Buzzell, R. I. (1979). Hypocotyl reactions and glyceollin in soybeans inoculated with zoospores of Phytophthora megasperma var. sojae. Phytopathology 69, 951-955.

Wei, P. C., Tan, F., Gao, X. Q., Zhang, X. Q., Wang, G. Q., Xu, H., et al. (2010). Overexpression of AtDOF4.7, an Arabidopsis DOF family transcription factor, induces floral organ abscission deficiency in Arabidopsis. Plant Physiol. 153, 1031-1045. doi: 10.1104/pp.110.153247

Wrather, J. A., Anderson, T. R., Arsyad, D. M., Tan, Y., Ploper, L. D., PortaPuglia, A., et al. (1997). Soybean disease loss estimates for the top 10 soybean producing countries in 1994. Plant Dis. 81, 107-110. doi: 10.1094/PDIS.1997. 81.1.107

Xu, P., Narasimhan, M. L., Samson, T., Coca, M. A., Huh, G. H., Zhou, J., et al. (1998). A nitrilase-like protein interacts with GCC Box DNA-binding proteins involved in ethylene and defense responses. Plant Physiol. 118, 867-874. doi: $10.1104 /$ pp.118.3.867

Xu, P. F., Wu, J. J., Allen, X., Li, W. B., Chen, W. Y., Wei, L., et al. (2012). Differentially expressed genes of soybean during infection by Phytophthora sojae. J. Integr. Agr. 11, 368-377.

Xu, Z. S., Chen, M., Li, L. C., and Ma, Y. Z. (2011). Functions and application of the AP2/ERF transcription factor family in crop improvement. J. Integr. Plant Biol. 53, 570-585. doi: 10.1111/j.1744-7909.2011.01062.x

Xu, Z. S., Xia, L. Q., Chen, M., Cheng, X. G., Zhang, R. Y., Li, L. C., et al. (2007). Isolation and molecular characterization of the Triticum aestivum $\mathrm{L}$. ethyleneresponsive factor 1 (TaERF1) that increases multiple stress tolerance. Plant Mol. Biol. 65, 719-732. doi: 10.1007/s11103-007-9237-9
Yamaguchi-Shinozaki, K., and Shinozaki, K. (1994). A novel cis-acting element in an Arabidopsis gene is involved in responsiveness to drought, low-temperature, or high-salt stress. Plant Cell 6, 251-264. doi: 10.1105/tpc.6.2.251

Yang, Z., Tian, L., Latoszek-Green, M., Brown, D., and Wu, K. (2005). Arabidopsis ERF4 is a transcriptional repressor capable of modulating ethylene and abscisic acid responses. Plant Mol. Biol. 58, 585-596. doi: 10.1007/s11103-005-7294-5

Yoo, S. D., Cho, Y. H., and Sheen, J. (2007). Arabidopsis mesophyll protoplasts: a versatile cell system for transient gene expression analysis. Nat. Protoc. 2, 1565-1572. doi: 10.1038/nprot.2007.199

Zhai, Y., Li, J. W., Li, X. W., Lei, T. T., Yan, F., Zhao, Y., et al. (2013a). Isolation and characterization of a novel transcriptional repressor GmERF6 from soybean. Biol. Plant. 57, 26-32. doi: 10.1007/s10535-012-0146-7

Zhai, Y., Wang, Y., Li, Y. J., Lei, T. T., Yan, F., Su, L. T., et al. (2013b). Isolation and molecular characterization of GmERF7, a soybean ethylene-response factor that increases salt stress tolerance in tobacco. Gene 513, 174-183. doi: 10.1016/ j.gene.2012.10.018

Zhang, G. Y., Chen, M., Chen, X. P., Xu, Z. S., Guan, S., Li, L. C., et al. (2008). Phylogeny, gene structures, and expression patterns of the ERF gene family in soybean (Glycine max L.). J. Exp. Bot. 59, 4095-4107. doi: 10.1093/jxb/ern248

Zhang, G. Y., Chen, M., Chen, X. P., Xu, Z. S., Li, L. C., Guo, J. M., et al. (2010). Isolation and characterization of a novel EAR-motif-containing gene GmERF4 from soybean (Glycine max L.). Mol. Biol. Rep. 37, 809-818. doi: 10.1007/s11033-009-9616-1

Zhang, G. Y., Chen, M., Li, L. C., Xu, Z. S., Chen, X. P., Guo, J. M., et al. (2009). Overexpression of the soybean GmERF3 gene, an AP2/ERF type transcription factor for increased tolerances to salt, drought, and diseases in transgenic tobacco. J. Exp. Bot. 60, 3781-3796. doi: 10.1093/jxb/erp214

Zhang, H. W., Huang, Z. J., Xie, B. Y., Chen, Q., Tian, X., Zhang, X. L., et al. (2004). The ethylene-, jasmonate-, abscisic acid- and NaCl-responsive tomato transcription factor JERF1 modulates expression of GCC box-containing genes and salt tolerance in tobacco. Planta 220, 262-270. doi: 10.1007/s00425-004$1347-\mathrm{x}$

Zhang, H. W., Zhang, J. F., Quan, R. D., Pan, X. W., Wan, L. Y., and Huang, R. F. (2013). EAR motif mutation of rice OsERF3 alters the regulation of ethylene biosynthesis and drought tolerance. Planta 237, 1443-1451. doi: 10.1007/s00425-013-1852-x

Zhang, S. Z., Xu, P. F., Wu, J. J., Allen, X., Zhang, J. X., Li, W. B., et al. (2010). Races of Phytophthora sojae and their virulences on commonly grown soybean varieties in Heilongjiang, China. Plant Dis. 94, 87-91.

Zhao, Y., Cheng, S. F., Song, Y. L., Huang, Y. L., Zhou, S. L., Liu, X. Y., et al. (2015). The interaction between rice ERF3 and WOX11 promotes crown root development by regulating gene expression involved in cytokinin signaling. Plant Cell 27, 2469-2483. doi: 10.1105/tpc.15.00227

Zhou, J., Tang, X., and Martin, G. B. (1997). The Pto kinase conferring resistance to tomato bacterial speck disease interacts with proteins that bind a cis-element of pathogenesis-related genes. Embo. J. 16, 3207-3218. doi: 10.1093/emboj/16. 11.3207

Zhu, Z. G., Shi, J. L., Xu, W. R., Li, H. E., He, M. Y., Xu, Y., et al. (2013). Three ERF transcription factors from Chinese wild grapevine Vitis pseudoreticulata participate in different biotic and abiotic stress-responsive pathways. J. Plant Physiol. 170, 923-933. doi: 10.1016/j.jplph.2013.01.017

Conflict of Interest Statement: The authors declare that the research was conducted in the absence of any commercial or financial relationships that could be construed as a potential conflict of interest.

Copyright $\odot 2017$ Zhao, Chang, Qi, Dong, Wang, Fan, Jiang, Cheng, Chen, Han, Xu and Zhang. This is an open-access article distributed under the terms of the Creative Commons Attribution License (CC BY). The use, distribution or reproduction in other forums is permitted, provided the original author(s) or licensor are credited and that the original publication in this journal is cited, in accordance with accepted academic practice. No use, distribution or reproduction is permitted which does not comply with these terms. 